\title{
Greater deciduous shrub abundance extends tundra peak season and increases modeled net $\mathrm{CO}_{2}$ uptake
}

\author{
SHANNAN K. SWEET ${ }^{1}$, KEVIN L. GRIFFIN ${ }^{1,2}$, HEIDI STELTZER $^{3}$, LAURA GOUGH ${ }^{4}$ and \\ NATALIE T. BOELMAN ${ }^{1}$ \\ ${ }^{1}$ Lamont-Doherty Earth Observatory, Department of Earth and Environmental Sciences, Columbia University, Palisades, NY \\ 10964, USA, ${ }^{2}$ Department of Ecology, Evolution, and Environmental Biology, Columbia University, New York, NY 10027, USA, \\ ${ }^{3}$ Department of Biology, Fort Lewis College, Durango, CO 81301, USA, ${ }^{4}$ Department of Biology, University of Texas at Arlington, \\ Arlington, TX 76019, USA
}

\begin{abstract}
Satellite studies of the terrestrial Arctic report increased summer greening and longer overall growing and peak seasons since the 1980s, which increases productivity and the period of carbon uptake. These trends are attributed to increasing air temperatures and reduced snow cover duration in spring and fall. Concurrently, deciduous shrubs are becoming increasingly abundant in tundra landscapes, which may also impact canopy phenology and productivity. Our aim was to determine the influence of greater deciduous shrub abundance on tundra canopy phenology and subsequent impacts on net ecosystem carbon exchange (NEE) during the growing and peak seasons in the arctic foothills region of Alaska. We compared deciduous shrub-dominated and evergreen/graminoid-dominated community-level canopy phenology throughout the growing season using the normalized difference vegetation index (NDVI). We used a tundra plant-community-specific leaf area index (LAI) model to estimate LAI throughout the green season and a tundra-specific NEE model to estimate the impact of greater deciduous shrub abundance and associated shifts in both leaf area and canopy phenology on tundra carbon flux. We found that deciduous shrub canopies reached the onset of peak greenness 13 days earlier and the onset of senescence 3 days earlier compared to evergreen/graminoid canopies, resulting in a 10-day extension of the peak season. The combined effect of the longer peak season and greater leaf area of deciduous shrub canopies almost tripled the modeled net carbon uptake of deciduous shrub communities compared to evergreen/graminoid communities, while the longer peak season alone resulted in $84 \%$ greater carbon uptake in deciduous shrub communities. These results suggest that greater deciduous shrub abundance increases carbon uptake not only due to greater leaf area, but also due to an extension of the period of peak greenness, which extends the period of maximum carbon uptake.
\end{abstract}

Keywords: Alaska, arctic tundra, canopy phenology, $\mathrm{CO}_{2}$ flux, deciduous shrub abundance, net ecosystem exchange, normalized difference vegetation index (NDVI)

Received 21 May 2014 and accepted 18 November 2014

\section{Introduction}

Global air temperatures have increased by about $0.72{ }^{\circ} \mathrm{C}$ since 1950 (IPCC, 2013). Arctic air temperatures have increased more than twice that amount (about $2{ }^{\circ} \mathrm{C}$ ) over the same period (AMAP, 2012; Overland et al., 2012), resulting in a particularly strong warming trend in the Arctic (Chapin et al., 2005; McBean et al., 2006; Serreze \& Francis, 2006). Ecological responses have already become apparent (Walther et al., 2002; ACIA, 2004). Many regions, for instance, have experienced an earlier start and/or a later end to the growing season, resulting in longer growing seasons at the panArctic scale (Tucker et al., 2001; Jia et al., 2004). Some studies have found an increase in growing season

Correspondence: Shannan K. Sweet, tel. 607227 5616,

fax 845365 8150, e-mail: ssweet@ldeo.columbia.edu length of 12-14 days per decade at high northern latitudes of North America (Myneni et al., 1997; Zeng et al., 2011) and 6-7 days per decade in northern Eurasia (Zhou et al., 2001; Jeong et al., 2011). Other studies suggest the lengthening of the growing season has been more significant in Eurasia than in North America (Barichivich et al., 2013).

Some Arctic regions are also experiencing shifts toward an earlier peak season (i.e., the period of maximum tundra greenness) (Goetz et al., 2005, 2010; Jia et al., 2009; Tagesson et al., 2012). A longer peak season extends the period of maximum leaf out and photosynthetic activity (Kikuzawa, 1995; Oberbauer et al., 1998), which extends the period of maximum carbon (C) uptake within a given year (Richardson et al., 2009; Mbufong et al., 2014). This is especially important in the Arctic, which has extremely short growing seasons (often $<100$ days), and where an extension of just a few 
days can have significant effects on annual carbon uptake (van Wijk et al., 2003). Euskirchen et al. (2006), for instance, estimate that for each day the growing season is extended in the arctic tundra, net carbon uptake increases by $5.3 \mathrm{~g} \mathrm{C} \mathrm{m}^{-2} \mathrm{yr}^{-1}$. As the area of pan-arctic tundra that melts out annually covers approximately 6.5 million $\mathrm{km}^{2}$, this suggests that a 1-day extension of the growing season could increase the tundra biome's annual carbon uptake by $\sim 35$ tons.

While changes in air temperature (Hollister et al., 2005; Delbart \& Picard, 2007; Xu et al., 2013) and snow cover duration (Stow et al., 2004; Wipf, 2010; Pau et al., 2011) are key factors influencing recent shifts in arctic canopy phenology, other major changes may also be contributing. For example, over the same time period satellite sensors have observed changes in canopy phenology and growing season length, they have also detected an increase in the peak greenness of the arctic tundra (Bunn et al., 2007; Verbyla, 2008; Jia et al., 2009), as measured increases in the normalized difference vegetation index (NDVI). This greening has been attributed to increased growth of extant deciduous shrubs (primarily birch, willow, and alder) as well as the expansion of deciduous shrubs into nonshrub tundra that is typically dominated by evergreens, graminoids, and cryptogams (Jia et al., 2003; Olthof et al., 2008; Forbes et al., 2010; Fraser et al., 2011). These findings are supported by comparative photo-interpretation (Sturm et al., 2001b; Tape et al., 2006) and field surveys (Sturm et al., 2001a; Hinzman et al., 2005; Elmendorf et al., 2012). Deciduous shrubs are predicted to continue to expand their range and grow larger (Sturm et al., 2005; Wookey et al., 2009; Myers-Smith et al., 2011; Pearson et al., 2013), which is likely to result in the decline of shade-intolerant plant functional types, such as evergreens, graminoids, and cryptogams (Chapin et al., 1995; Cornelissen et al., 2001; Wahren et al., 2005; Walker et al., 2006). As it has been shown that deciduous shrub-dominated tundra communities have accelerated green-up rates (Vierling et al., 1997), and reach peak NDVI earlier compared to graminoid and evergreen-dominated tundra (Jia et al., 2004), we hypothesized that the increased abundance of deciduous shrubs is likely contributing to satellite observations of earlier tundra peak seasons (Goetz et al., 2005, 2010; Tagesson et al., 2012) and that this in turn is enhancing seasonal carbon uptake by tundra vegetation.

To test these hypotheses at a plot-level scale, we tracked community-level phenology of deciduous shrub-dominated and evergreen/graminoid-dominated canopies in the arctic foothills region of Alaska throughout the duration of the 2013 growing season. We determined canopy phenology metrics (i.e., onset of greening, onset of peak green, and onset of senescence) by applying both threshold analysis and piecewise linear regression modeling to curves of growing season near-surface measurements of daily plot-level NDVI. We then estimated leaf area index (LAI) using previously determined NDVI-LAI relationships for arctic vegetation (Street et al., 2007) and used the arctic-specific model of Shaver et al. (2007) to predict net ecosystem exchange (NEE) throughout the green season. A number of studies have shown differences in canopy phenology among different tundra types (e.g., Vierling et al., 1997; Jia et al., 2004; Narasimhan \& Stow, 2010), as well as differences between tundra vegetation communities in net carbon flux (e.g., Shaver et al., 2007; Street et al., 2007). However, to our knowledge, this is the first field study to combine both, with a focus on peak season length, and to make comparisons between naturally occurring deciduous shrub and evergreen/ graminoid tundra communities. This approach allows us to determine the influence of deciduous shrub abundance on canopy phenology and to estimate the relative effect of deciduous shrub abundance on net ecosystem carbon exchange.

\section{Methods}

\section{Study sites}

Datasets were collected from snowmelt until snowfall in 2013 (from 1 June to 5 September) at two field sites, near the Sagavanirktok River-Department of Transportation camp (SDOT) and Imnavait Creek (IMVT) (Fig. 1). Average elevation at IMVT is $\sim 900 \mathrm{~m}$ and at SDOT is $\sim 500 \mathrm{~m}$. The two field sites are located in the vicinity (within $\sim 30 \mathrm{~km}$ ) of Toolik Field Station in the northern foothills of the Brooks Range, Alaska $\left(68^{\circ} 38^{\prime} \mathrm{N}, 149^{\circ} 34^{\prime} \mathrm{W}\right)$. Annual precipitation at Toolik is 200 $400 \mathrm{~mm}$, with $45 \%$ falling as snow (van Wijk et al., 2005). The average growing season at Toolik extends from approximately late May/early June until mid- to late August, during which time the average air temperature (air T) is $7{ }^{\circ} \mathrm{C}$ (Johnson et al., 2000). Based on the canopy greenness metrics derived from our seasonal NDVI measurements, we define the growing season as the period from the onset of greening (shortly after snowmelt) until the end of senescence (after prolonged snowfall) and define the peak season as the period from the onset of peak greenness until the onset of senescence. Although both field sites experienced delayed snowmelt in 2013 relative to the three previous years, air $T$ and photosynthetically active radiation (PAR) throughout the 2013 growing season (Fig. S1) were within the average range of values for Toolik (Johnson et al., 2000; Heskel et al., 2013).

In May 2010, two $20000 \mathrm{~m}^{2}$ study areas were selected at each field site: one evergreen/graminoid study area (EG; the 'Open' areas in Sweet et al., 2014) and one deciduous shrub study area (DS; the 'Shrub' areas in Sweet et al., 2014). Two $100 \mathrm{~m}$ transects were established within each EG and DS study area at each field site (for a total of 8 transects), and ten 


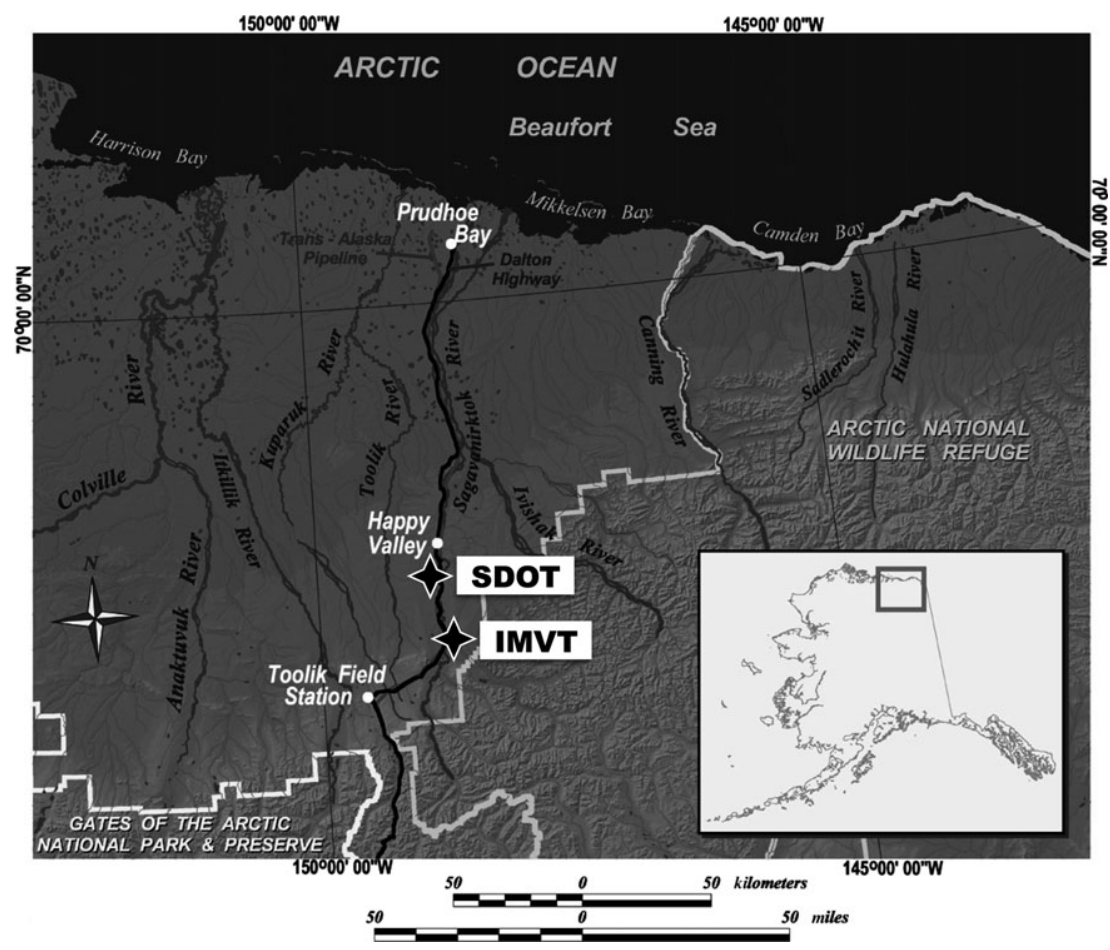

Fig. 1 Map of Alaska and the north slope of the Brooks Range (inset) showing the location of the two field sites near the Toolik Lake field station used in this study. IMVT, Imnavait Creek; SDOT, Sagavanirktok River-Department of Transportation.

$1 \mathrm{~m}^{2}$ quadrats were established at $10 \mathrm{~m}$ intervals along each transect (for a total of 80 quadrats). Because only 18 instruments were available to measure canopy phenology for this study, two to three quadrats along each transect were chosen to best represent vegetation communities with naturally occurring maximum and minimum deciduous shrub dominance (see Percent vegetation cover). In total, we monitored nine DS ( $n=4$ at IMVT and 5 at SDOT) and nine EG ( $n=5$ at IMVT and 4 at SDOT) canopies.

\section{Percent vegetation cover}

Plant cover was measured in each $1 \mathrm{~m}^{2}$ quadrat in late July (period of maximum leaf area) of 2010 by placing a frame outlining $20 \mathrm{~cm} \times 20 \mathrm{~cm}$ subquadrats over each $1 \mathrm{~m}^{2}$ quadrat and visually estimating the plant canopy from directly above, with groups summing to $100 \%$. The cover of leaves and plants hidden by over story vegetation was not included, which may have led to an underestimate for low-lying plants such as mosses in some quadrats. Based on this percent cover data (Fig. S2), we selected nine DS quadrats that contained high percent cover of deciduous shrubs (ranging from $\sim 30 \%$ to 90\%) (mainly Betula nana and Salix spp.), and low percent cover of evergreens and graminoids (ranging from $\sim 1 \%$ to $30 \%$ ). We also selected nine EG quadrats that contained low percent cover of deciduous shrubs (ranging from $\sim 7 \%$ to $30 \%$ ) and high percent cover of evergreens and graminoids (ranging from $\sim 20 \%$ to $70 \%$ ). DS and EG canopies had similar amounts of moss cover and were interspersed with forbs and lichens.

\section{Canopy phenology}

Spectral reflectance measurements and calculation of NDVI. Seasonal broadband $\mathrm{NDVI}_{\text {broadband }}$ was calculated using two light sensors (Fig. S3): (1) a PAR smart sensor and (2) a Silicon Pyranometer smart sensor (Onset Computer Corporation, Bourne, MA, USA). Prior to snowmelt, downwardlooking light sensors were fitted with cylindrical sheaths (Fig. S3) to limit the full angle cone of acceptance field of view (FOV) to $45^{\circ}$ and sensors were positioned $50 \mathrm{~cm}$ above the top of the canopy in each $1 \mathrm{~m}^{2}$ quadrat, so that each measurement's circular footprint was approximately $0.75 \mathrm{~m}^{2}$. Light sensors measured canopy reflectance every two minutes from 1 June to 5 September, 2013, and data were stored on a HOBO Weather Station logger (Onset Computer Corporation). Only $\mathrm{NDVI}_{\text {broadband }}$ values collected between 1200 and 1400 local time were used because solar noon occurs between 1300 and 1330 during the growing season in our study region.

In one quadrat at each of the two sites, the same set of light sensors were placed looking upward to measured incoming light conditions for calibration references and to filter data (H. Steltzer, R. Shory and G. Chong, unpublished results). Upward-looking sensors were not sheathed and thus incorporated incoming solar light from the full upper hemisphere. Filters were developed to select clear sky data points. First, a clear day was selected by visual inspection of irradiance charts. A clear day has a characteristic smooth bell-shaped curve easily distinguished from the jagged curves of cloudy days. Based on this index day, thresholds were generated. For 
each sensor, the maximum irradiance value on the index day was internally extracted. This was the sensor's clear sky noon value (CSNV). Thresholds for each sensor were generated as 75-125\% of the CSNV for that sensor. At each time point, if any of the sensor reading needed for $\mathrm{NDVI}_{\text {broadband }}$ was outside the thresholds for that sensor, $\mathrm{NDVI}_{\text {broadband }}$ was not calculated for that time point for that instrument. Clear sky conditions occurred frequently enough so that $80-120$ values were obtained each day. Occasionally, an entire day's data were rendered invalid due to persistent inclement weather conditions (e.g., continuous precipitation or snow cover), and these data points were removed.

Eqns (1) through (3), adapted from methods outlined in Huemmrich et al. (1999) and described in H. Steltzer, R. Shory and G. Chong (unpublished results), were used to calculate $\mathrm{NDVI}_{\text {broadband }}$ from the two light sensors. PAR sensors recorded photosynthetically active radiation ( $\mu \mathrm{mol}$ photons $\mathrm{m}^{-2} \mathrm{~s}^{-1}$ ) over a broad visible band (PAR: 400-700 nm). Pyranometer sensors recorded irradiance $\left(\mathrm{W} \mathrm{m}^{-2}\right)$ over a broad visible and infrared (shortwave) band (SW: 300$1100 \mathrm{~nm}$ ). First, PAR measurements were converted to units of $\mathrm{W} \mathrm{m}{ }^{-2}$ by multiplying by $0.21 \mathrm{~J} \mathrm{~mol}^{-1}$ (Huemmrich et al., 1999; Shory, 2014; H. Steltzer, R. Shory and G. Chong, unpublished results). PAR reflectance ( $\rho$ PAR) was then calculated using Eqn (1), where $E_{\text {PARrefl }}$ and $E_{\text {PARin }}\left(\mathrm{W} \mathrm{m}^{-2}\right)$ are the reflected and incoming PAR values, respectively. Optical infrared reflectance ( $\rho$ OIR) was calculated using Eqn (2), where $E_{\mathrm{SWin}}$ and $E_{\mathrm{SWrefl}}\left(\mathrm{W} \mathrm{m}^{-2}\right)$ are the shortwave (visible + infrared) irradiances for both incoming and reflected fluxes, respectively. These reflectance values were then used to calculate a broadband NDVI broadband using Eqn (3).

$$
\begin{gathered}
\rho \mathrm{PAR}=\frac{E_{\text {PARrefl }}}{E_{\text {PARin }}} \\
\rho \mathrm{OIR}=\frac{E_{\text {SWrefl }}-E_{\text {PARrefl }}}{E_{\text {SWin }}-E_{\text {PARin }}} \\
\text { NDVI }_{\text {broadband }}=\frac{\rho \mathrm{OIR}-\rho \mathrm{PAR}}{\rho \mathrm{OIR}+\rho \mathrm{PAR}}
\end{gathered}
$$

In addition to high temporal resolution $\mathrm{NDVI}_{\text {broadband }}$ data from PAR and pyranometer sensors, we also collected weekly high spectral resolution reflectance data in all quadrats from 1 June to 16 July, 2013, with a field portable spectroradiometer (FieldSpec3; Analytical Spectral Devices, Boulder, CO,

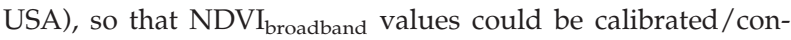
verted and used to calculate leaf area (see Leaf area index model). The FieldSpec 3 has a $25^{\circ}$ full angle cone of acceptance FOV with a spectral sampling interval of $1.4 \mathrm{~nm}$. FieldSpec3 radiance measurements were preceded by a calibration scan of a 99\% reflectance white standard (Spectralon; LabSphere, North Sutton, NH, USA) to normalize for changes in light conditions between measurements. The foreoptic was held $1 \mathrm{~m}$ above the top of the canopy, so that each measurement's circular footprint was approximately $0.15 \mathrm{~m}^{2}$. Five measurements were made within each $1 \mathrm{~m}^{2}$ quadrat to capture spatial heterogeneity. Spectral measurements were converted to reflectance values, and $\mathrm{NDVI}_{\text {spectroradiometer }}$ was calculated using Eqn (4) from visible red (R: 650-690 nm) and near- infrared (NIR: 750-850 nm) reflectance. The five NDVI values associated with each quadrat were averaged to give a mean quadrat value.

$$
\mathrm{NDVI}_{\text {spectroradiometer }}=\frac{\mathrm{NIR}-\mathrm{R}}{\mathrm{NIR}+\mathrm{R}}
$$

$\mathrm{NDVI}_{\text {spectroradiometer }}$ and $\mathrm{NDVI}_{\text {broadband }}$ values showed a strong linear correlation $\left(R^{2}=0.85, P<0.001, F_{1,120}=712.3\right.$; Fig. S4). We used this linear relationship (Eqn 5) to convert $\mathrm{NDVI}_{\text {broadband }}$ values to calculate leaf area with higher precision. Converted values are hereafter referred to as NDVI.

$$
y=2.13085 x-0.91531
$$

Determination of phenological metrics. Prior to determining phenological metrics, a locally weighted regression (loess) was used to smooth data (Cleveland, 1979; Cleveland \& Loader, 1996). To produce a relatively smooth curve while still capturing the important and intrinsic structure of the data, we set the smoothing parameter $(\alpha)=0.2$ (Jacoby, 2000). Although $\alpha$ values $>0.5$ are often used for highly variable and scattered data (Cleveland \& Loader, 1996; Jacoby, 2000), we chose 0.2 because lower parameters $(\alpha<0.2)$ did not smooth the curve enough, yet our data were not so variable that we needed to use a high value $(\alpha>0.2)$, which would have removed valuable information in the seasonal NDVI curves used to determine precise phenological parameters. After smoothing, we used two methods (threshold analysis and piecewise regression modeling) to determine the date [day of the year (DOY)] of three canopy phenology metrics for each of the 18 seasonal NDVI curves: (1) onset of greening; (2) onset of peak green; and (3) onset of senescence. The fourth phenological metric, end of senescence (4), was determined as the date on which NDVI values dropped dramatically following multiple days of snowfall/snow cover, which occurred on 5 September (DOY 248) for all quadrats. Quadrat-specific dates on which each phenological metric was reached - as determined by both methods - can be found in Fig. S5.

Although there are several methods to model land surface phenology from remotely sensed data (White et al., 2009; Klosterman et al., 2014), we chose thresholds and piecewise linear regression modeling for the following reasons. Thresholds are commonly used and considered to be the simplest method for phenological studies using NDVI (de Beurs \& Henebry, 2010; Zeng et al., 2011). However, threshold analysis can be problematic given the variability of NDVI among different sensors (van Leeuwen et al., 2006; Zeng et al., 2011), across different regions (White et al., 2003), and over time. Although using the ratio method developed by Kogan (1995) alleviates some of the problems with using thresholds (White et al., 1997), threshold analysis may not be optimal when dealing with high temporal resolution NDVI data that exhibit daily variations and that have not been obtained throughout an entire 365-day year (de Beurs \& Henebry, 2010). In contrast, piecewise linear regression modeling has the potential to find precise inflection points (Vieth, 1989) without relying on thresholds (Zhang et al., 2003; Chandola et al., 2010) and allows for the variable temporal nature of NDVI curves (de Beurs \& Henebry, 2010). Further, piecewise analysis best-matched our view of seasonal 
canopy development (e.g., that the onset of greening is when vegetation begins to quickly green, and that the peak season is when the canopy is constant in greenness) and has been successful in identifying ecological thresholds (Toms \& Lesperance, 2003; Wang et al., 2011) and modeling inflection points in NDVI data (Piao et al., 2011; Sun et al., 2011; Zhang et al., 2013).

For threshold analysis, a locally tuned NDVI threshold was used (White et al., 1997; de Beurs \& Henebry, 2010), where the state of the ecosystem is indexed by transforming the NDVI to a 0 to $1 \mathrm{NDVI}_{\text {ratio, }}$ using Eqn (6), where NDVI is the daily NDVI, and $\mathrm{NDVI}_{\max }$ and $\mathrm{NDVI}_{\min }$ are the seasonal maximum and minimum of the NDVI curve, respectively. Onset of greening was defined as the date when the $\mathrm{NDVI}_{\text {ratio }}$ value of 0.5 was exceeded. Onset of peak green was defined as the date

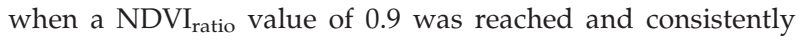
exceeded. Onset of senescence was defined as the date when $\mathrm{NDVI}_{\text {ratio }}$ values dropped below 0.9 .

$$
\mathrm{NDVI}_{\text {ratio }}=\frac{\mathrm{NDVI}-\mathrm{NDVI}_{\min }}{\mathrm{NDVI}_{\max }-\mathrm{NDVI}_{\min }}
$$

Piecewise linear regression modeling was applied to seasonal NDVI curves using the 'segmented' package in $R$ ( $R$ Core Team, 2014). The conceptual framework and mathematical calculations used to find inflection points in nonlinear models are detailed in Muggeo $(2003,2008)$. Onset of greening was defined as the point in the curve (i.e., the date) when NDVI began to increase rapidly following snowmelt. Onset of peak green was defined as the point in the curve when NDVI began to level out. Onset of senescence was defined as the point in the curve when NDVI began to decrease. Prior to modeling, phenology metrics were visually estimated in Excel (Microsoft ExcEL 2008 for Mac, v. 12.0, Redmond, WA, USA) and inflection points determined from piecewise modeling closest to visual estimates and with the lowest standard errors were chosen as representative dates.

Using the above four canopy phenology metrics determined via both the threshold and piecewise regression techniques, we calculated growing season length (from the onset of greening to the end of senescence) and peak season length (from the onset of peak green to the onset of senescence) for each quadrat. To determine the daily rate of change in NDVI during green-up (i.e., rate of green-up), linear slopes of the segments of NDVI curves from the onset of greening to the onset of peak green were calculated. These canopy metrics were determined for each of the 18 quadrats, and means were then calculated for DS $(n=9)$ and EG $(n=9)$ canopies. Although we present phenology metrics determined from both threshold and piecewise regression methods, we used dates determined from piecewise regressions to model NEE (see Net ecosystem exchange model) for several reasons. First, both methods yielded similar results for the onset of peak green and the onset of senescence (Fig. S5). Also, because piecewise regression analysis is more robust, it better matched our view of seasonal canopy development in terms of the onset of greening (e.g., that the onset of greening is when NDVI increases rapidly after a flat period following snowmelt).

\section{Leaf area index model}

Calibrated daily values of canopy NDVI were used to model daily changes in LAI (Eqn 7) in $\mathrm{m}^{2}$ leaf $\mathrm{m}^{-2}$ ground using the model developed by Street et al. (2007).

$$
\mathrm{LAI}=a * e^{b * \mathrm{NDVI}}
$$

Model parameters in Eqn (7) were varied for each quadrat depending on species composition (see table 1 in Street et al., 2007), which was determined from our percent cover data described above. Parameters from Street et al.(2007) for Betula and Salix vegetation communities were used to derive DS canopy LAI, and parameters for Tussock and Sedge vegetation communities were used to derive EG canopy LAI (Table S1). Although this NDVI-LAI model does not explicitly include biophysical variables (e.g., leaf layering and orientation) (Baret \& Guyot, 1991), the model parameters from Street et al. (2007) were chosen because these vegetation-specific parameters were derived from nearby low Arctic sites (including from our IMVT site) with similar vegetation characteristics as those used in this study and take into account changes in leaf area across different vegetation communities. Also, although other studies have developed models to estimate LAI using NDVI through space (van Wijk \& Williams, 2005; Steltzer \& Welker, 2006), the relationships derived by Street et al. (2007) were developed from mid-June through August and include changing canopy phenology dynamics over time. It is important to note that this LAI model was not developed during senescence and assumes changes in NDVI are due to changes in leaf area. However, after the onset of senescence, reductions in NDVI are due to changes in both leaf color and leaf area. To capture trends during the period of rapid greening that occurs shortly after snowmelt, we therefore defined a new period termed the 'green season', which extends from the onset of greening to the onset of senescence, and modeled LAI data during this green season period only.

\section{Net ecosystem exchange model}

Net ecosystem exchange of $\mathrm{CO}_{2}$ (NEE) was calculated using the model of Shaver et al. (2007) (Eqn 8 through 10), using measurements of PAR and air $T$ made every two minutes throughout the season, and daily estimates of LAI based on the midday measurements of NDVI described above. Because it has been shown that photosynthesis per unit leaf area is relatively constant throughout the growing season in the Alaskan arctic tundra (Heskel et al., 2013), knowing only the amount of leaf area of the canopy (as estimated by LAI), as well as PAR and air T, allows for reasonable estimation of NEE throughout the season even though the NEE model was developed midseason.

NEE $\left(\mu \mathrm{mol} \mathrm{CO} \mathrm{CO}_{2} \mathrm{~m}^{-2} \mathrm{~s}^{-1}\right.$ ), calculated using Eqn (8), is the difference between overall ecosystem respiration $\left(R_{\mathrm{E}}\right)$ and gross primary production (GPP), where negative values of NEE represent net $\mathrm{CO}_{2}$ uptake. We used parameter values for $P_{\operatorname{maxL}}, k, E_{0}, \beta, R_{0}$, and $R_{\mathrm{X}}$ as determined by Shaver $e t$ al. (2013) for the low Arctic. 


$$
\mathrm{NEE}=R_{\mathrm{E}}-\mathrm{GPP}
$$

$R_{\mathrm{E}}$ was calculated using Eqn (9), where $R_{0}(1.177 \mu \mathrm{mol}$ $\mathrm{CO}_{2} \mathrm{~m}^{-2}$ leaf s${ }^{-1}$ ) is the basal respiration rate, which accounts for a majority of both autotrophic and heterotrophic respiration (Shaver et al., 2013), and varies with changes in LAI, the parameter $\beta\left(0.046{ }^{\circ} \mathrm{C}^{-1}\right)$, and air $T\left({ }^{\circ} \mathrm{C}\right)$. Air $T$ used in Eqn (9) was recorded $\sim 50 \mathrm{~cm}$ above ground level in all 18 quadrats with a HOBO TMC20-HD Sensor Onset Computer Corporation. The additional source of respiration in Eqn (9), $R_{\mathrm{x}}$ $\left(0.803 \mu \mathrm{mol} \mathrm{CO}_{2} \mathrm{~m}^{-2}\right.$ ground $\left.\mathrm{s}^{-1}\right)$, comes from deeper soil horizons and is independent of LAI and short-term fluctuations in air $T$ (Shaver et al., 2007). $R_{\mathrm{x}}$ was added to the model because it improves accuracy of predictions and the fit of the model, and prevents $R_{\mathrm{E}}$ from going to zero when there is no leaf area (Shaver et al., 2007).

$$
R_{\mathrm{E}}=\left(R_{0} * e^{\beta * \operatorname{air} T} * \mathrm{LAI}\right)+R_{\mathrm{x}}
$$

GPP was calculated using Eqn (10), where $P_{\operatorname{maxL}}$ $\left(14.747 \mu \mathrm{mol} \mathrm{m}{ }^{-2}\right.$ leaf s$\left.{ }^{-1}\right)$ is the light saturated photosynthetic rate per unit leaf area, $k\left(0.5 \mathrm{~m}^{-2}\right.$ ground $\mathrm{m}^{-2}$ leaf $)$ is a Beer's law extinction coefficient, and $E_{0}(0.041 \mu \mathrm{mol} \mathrm{CO}$ fixed $\mu \mathrm{mol}^{-1}$ photons absorbed) is the initial slope of the light response curve. Incoming solar irradiance $(I)$, which is the top-of-the-canopy photosynthetic photon flux density

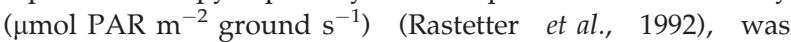
recorded $\sim 50 \mathrm{~cm}$ above the canopy in one quadrat at each site using upward-looking PAR sensors described above. All $I$ and air $T$ data (Fig. S1) were recorded every $2 \mathrm{~min}$ from June 1 to September 5, 2013, and stored on a HOBO Weather Station logger (Onset Computer Corporation).

$$
\mathrm{GPP}=\frac{P_{\operatorname{maxL}}}{k} * \ln \frac{P_{\operatorname{maxL}}+E_{0} * I}{P_{\operatorname{maxL}}+E_{0} * I * e^{(-k * \mathrm{LAI})}}
$$

We calculated $R_{\mathrm{E}}, \mathrm{GPP}$, and $\mathrm{NEE}\left(\mu \mathrm{mol} \mathrm{CO} \mathrm{CO}^{-2} \mathrm{~s}^{-1}\right)$ at 2-min intervals through each day $(24 \mathrm{~h})$ for each of the 18 quadrats and estimated seasonal NEE based on each quadrat's respective phenology dates derived from piecewise linear regression analysis. Total peak season NEE $\left(\mathrm{g} \mathrm{C} \mathrm{m}^{-2}\right.$ season $^{-1}$ ) was estimated by integrating daily average NEE values from the onset of peak green to the onset of senescence. As with LAI, the NEE model was not developed after the period of senescence, and because modeled LAI was used for NEE calculations, we modeled NEE data during the green season only. Because we did not estimate total growing season NEE, to capture the period of green-up/leaf expansion (prior to peak green), we estimated total green season NEE $\left(\mathrm{g} \mathrm{C} \mathrm{m}^{-2}\right.$ season $^{-1}$ ) by integrating daily average NEE values from the onset of greening to the onset of senescence. To tease out the effect of differences in leaf area between communities and further examine the effect of changing season length on NEE, total integrated NEE was also estimated for all nine DS quadrats using average EG peak and green season dates, as well as for all nine EG quadrats using average DS peak and growing season dates (see Statistical analysis).

The NEE model used in this study has been tested across a wide array of arctic ecosystems. For instance, in comparing 1410 modeled vs. in situ measured $\mathrm{CO}_{2}$ flux measurements from Alaskan and Swedish arctic sites, Shaver et al. (2007) found the NEE model confidently predicted $\mathrm{CO}_{2}$ fluxes $\left(R^{2}=0.8\right)$ with no a priori knowledge of species composition and using model inputs of only PAR, air $T$, and LAI derived from NDVI. Further testing of the model using eddy covariance data was performed by Rastetter et al. (2010), where they were able to reliably predict NEE for all major vegetation types in the low Arctic $\left(R^{2}>0.77\right)$. Still further testing performed by Shaver et al. (2013) across the pan-Arctic showed good agreement between 4834 measured vs. predicted NEE $\left(R^{2}=0.76\right)$. The model has also proven effective at predicting fluctuations in NEE over large regions using satellite-derived NDVI. Loranty et al. (2010), for instance, used MODIS satellite-based estimates of NDVI to calculate LAI and predict NEE over approximately $1 \mathrm{~km}^{2}$ at low arctic sites in Alaska and Canada. Across a wide range of sites and years, Loranty et al. (2010) found good agreement between NEE measured at eddy covariance towers and modeled NEE $\left(R^{2}=0.76\right)$.

\section{Model sensitivity analysis}

We assessed the sensitivity of modeled NEE to changes in air $T$, PAR, LAI, and the onset date of the peak season by varying the original/baseline values of these four parameters by $\pm 10 \%, 20 \%$, and $30 \%$ for each quadrat. We then recalculated NEE for every 2-min interval (applying the same methods described above). The percent changes in model parameters were applied equally across both DS and EG canopies. A peak season beginning on DOY 189 and 40 days long was assumed as the baseline value because this was the average date of onset and length of the peak season across all DS and EG canopies using piecewise regression analysis.

\section{Statistical analysis}

Data were checked for normality in distribution and homogeneity of variances using the Shapiro-Wilk and Bartlett's tests. Data that did not meet assumptions of normality (ShapiroWilk: $P<0.05)$ and/or homogeneity (Bartlett's: $P<0.05)$ were log- or square-root-transformed prior to statistical analysis. For all between-subject tests, we report Wilks' Lambda results. Differences were considered significant at $P<0.05$. All statistical analysis was performed in R (R Core Team, 2014).

A multivariate analysis of variance (MANOVA) was conducted to test for differences in the three canopy-level phenology stages between canopy types ( $n=9$ DS canopy, $n=9$ EG canopy), with site (IMVT and SDOT) as a blocking factor. Main effects determined from both phenology analysis methods are reported in tables, and main and interaction effects from results of piecewise regression analysis are reported in the text.

One-way analysis of variance (ANOVA), with site as a blocking factor, was used to test for differences between canopy types in the rate of green-up, growing and peak season lengths, and total green season and peak season NEE.

One-way ANOvA, with site as a blocking factor, was also used to test the effects of changing season length on total green and peak season NEE (determined using piecewise regression phenology dates) within each canopy type. To do 
this, NEE was estimated for all quadrats using average DS and EG green and peak season lengths. And changes in total green season NEE with changing season length were compared within vegetation communities (i.e., DS NEE at 63 days was compared to DS NEE at 68 days; and EG NEE at 63 days was compared to EG NEE at 68 days). The same comparison was made for peak seasons within each vegetation community (DS NEE at 44 days compared to at 34 days; EG NEE at 44 days compared to at 34 days).

A repeated measures ANOVA, with date and canopy type as the main effects and site as a blocking factor, was used to test for differences between canopy types for variables measured (NDVI) or modeled (LAI, $R_{\mathrm{E}}, \mathrm{GPP}$, and NEE) repeatedly throughout the season.

Linear regression models were used to evaluate relationships between percent cover of deciduous shrubs and (1) onset of greening, (2) rate of green-up, (3) onset of peak green, (4) onset of senescence, (5) peak season length, (6) growing season length, (7) green season NEE, and (8) peak season NEE.

\section{Results}

\section{Canopy phenology}

Following snowmelt, DS canopies had lower NDVI values than EG canopies (Fig. 2), but faster greening rates quickly led to greater NDVI values in DS canopies (effect of date*canopy type: NDVI $-P<0.01$, $\left.F_{1,248}=14.54\right)$. Although the pattern of NDVI changed throughout the season (effect of date: NDVI $\left.P<0.001, F_{1,88}=51.04\right)$ and differed between sites (effect of site: NDVI $-P<0.001, F_{1,248}=332.16$ ), DS canopies maintained higher NDVI values than EG canopies throughout the majority of the season (effect of canopy type: NDVI $-P<0.001, F_{1,248}=702.15$ ).

The pattern of canopy phenology (Fig. 2 and Table 1a) differed between canopy types (effect of canopy type: phenology $\left.-P<0.001, F_{3,13}=12.85\right)$ and sites (effect of site: phenology $-P<0.001, F_{3,13}=18.78$ ) largely due to earlier onset of the peak season and onset of senescence for DS canopies in general, and at SDOT in particular. Because DS canopies reached the onset of greening 2 days later $(P<0.05)$ than EG canopies (Table 1a), but ended senescence at the same time (DOY 248), the growing season length was 2 days shorter for DS compared to EG canopies (Table 1b). However, because DS canopies had an accelerated rate of green-up $(P<0.001)$, they reached the onset of peak green 13 days earlier than EG canopies $(P<0.001)$. In addition, DS canopies reached the onset of senescence only 3 days earlier than EG canopies. Thus, although SDOT had faster green-up rates (effect of site: green-up rate $\left.-P<0.05, F_{1,15}=5.54\right)$ and longer peak seasons compared to IMVT (effect of site peak season length: $P<0.05, F_{1,15}=13.31$ ), the average peak season for all
DS canopies (SDOT and IMVT combined) was 10 days longer $(P<0.05)$ compared to EG canopies (Table $1 b)$.

To further examine the effect of increasing deciduous shrub cover on canopy phenology and season length, we evaluated the relationship between percent deciduous shrub cover and canopy phenology variables across all quadrats (Fig. 3). We found that, although the onset of greening did not occur earlier as deciduous shrub cover increased, the rate of green-up became significantly faster $\left(R^{2}=0.7, P<0.001, F_{1,16}=37.59\right.$; Fig. $\left.3 \mathrm{~b}\right)$ and the onset of peak green occurred significantly earlier $\left(R^{2}=0.8, P<0.001, F_{1,16}=58.64\right.$; Fig. $\left.3 c\right)$. Although increasing deciduous shrub cover did not affect the date of the onset of senescence, nor the overall growing season length, the peak season lengthened significantly $\left(R^{2}=0.71, P<0.001, F_{1,16}=39.38\right.$; Fig. 3e $)$.

\section{Leaf area index model}

Similar to the pattern of NDVI, the increase in the LAI during green-up was more pronounced for DS compared to EG canopies (effect of date*canopy type: LAI $-P<0.001, F_{1,203}=25.44$; Fig. 4a). Although the pattern of LAI changed throughout the season (effect of date: LAI $\left.-P<0.001, F_{1,71}=93.6\right)$, DS canopies maintained higher LAI throughout most of the green season compared to EG canopies (effect of canopy type: LAI $\left.-P<0.001, F_{1,203}=1070.86\right)$. As with NDVI, SDOT maintained higher LAI values compared to IMVT throughout most of the green season (effect of site: LAI $P<0.001, F_{1,203}=318.6$ ).

\section{Net ecosystem exchange model}

The change in respiration $\left(R_{\mathrm{E}}\right)$ during green-up and senescence was more pronounced for DS compared to EG canopies (effect of date*canopy type: $R_{\mathrm{E}}-$ $P<0.001, F_{1,203}=33.59$; Fig. $\left.4 b\right)$. Throughout most of the green season, although the pattern of $R_{\mathrm{E}}$ changed (effect of date: $R_{\mathrm{E}}-P<0.05, F_{1,71}=43.8$ ), DS canopies had greater $\mathrm{CO}_{2}$ release from $R_{\mathrm{E}}$ compared to EG canopies (effect of canopy type: $R_{\mathrm{E}}-P<0.001$, $F_{1,203}=1030.81$ ). There was also a difference between sites because SDOT maintained higher $R_{\mathrm{E}}$ values compared to IMVT throughout most of the green season (effect of site: $R_{\mathrm{E}}-P<0.001, F_{1,203}=414.36$ ).

Similar to $R_{\mathrm{E}}$, there was a significant interaction effect for the overall GPP data (effect of date*canopy type: GPP $-P<0.001, F_{1,203}=11.61$; Fig. 4c) and the pattern of GPP changed throughout the season (effect of date: GPP $\left.-P<0.001, F_{1,71}=13.26\right)$. Also similar to $R_{\mathrm{E}}$, throughout most of the green season, DS canopies had greater $\mathrm{CO}_{2}$ uptake from GPP compared to EG canopies (effect of canopy type: GPP $-P<0.001, F_{1,203}=969.14$ ), 


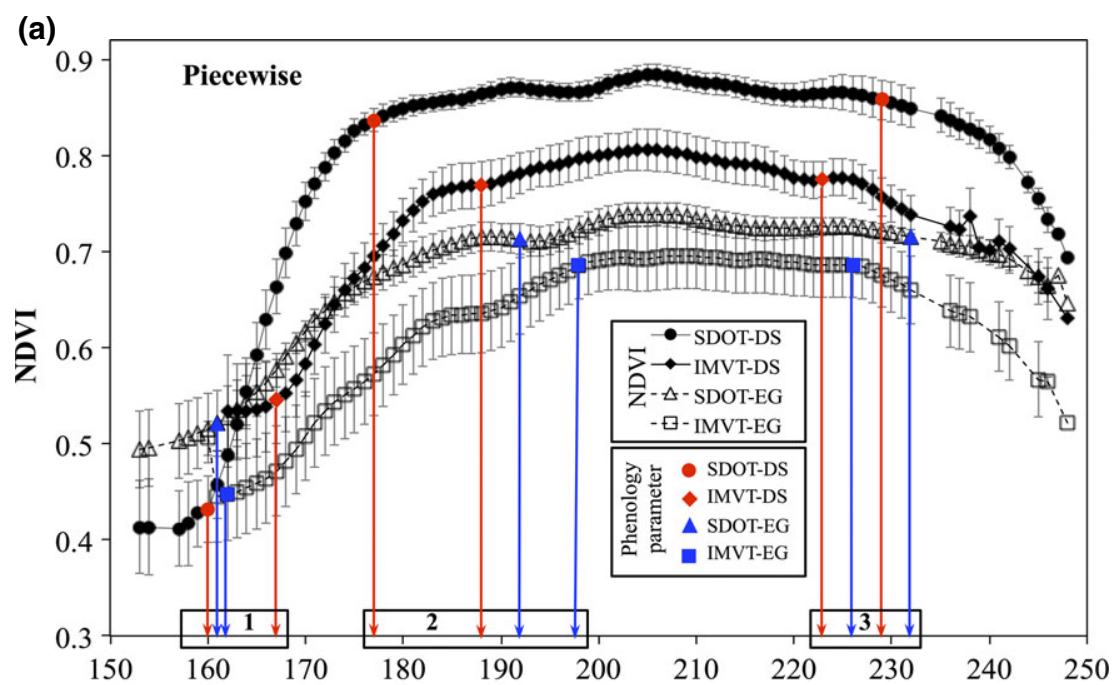

(b)

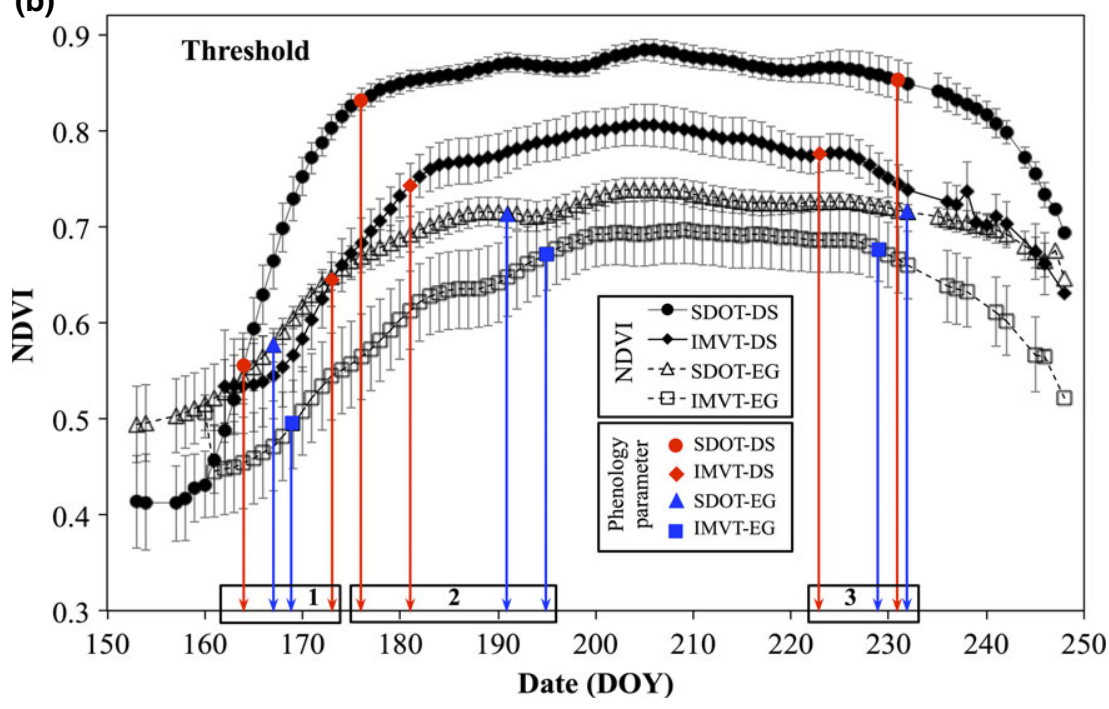

Fig. 2 Seasonal canopy greenness [loess smoothed normalized difference vegetation index (NDVI)] for deciduous shrub (DS) and evergreen/graminoid (EG) canopies at each of the two study sites. Error bars represent 1 standard error of the mean (SEM). On the respective NDVI curves, dates when canopy phenology metrics were reached are marked with red (DS) and blue (EG) points, with arrows of matching colors extended to the $x$-axis. Canopy phenology parameters are indicated by numbered boxes on the $x$-axis: (1) onset of greening, (2) onset of peak greenness, and (3) onset of senescence. Figure (a) represents dates determined using piecewise linear regression analysis and (b) represents dates determined using threshold analysis.

and SDOT maintained higher GPP values compared to IMVT (effect of site: GPP $-P<0.001, F_{1,203}=305.59$ ).

The pattern of change throughout the season in NEE was similar for both DS and EG canopies (Fig. 4d). However, DS canopies had greater net $\mathrm{CO}_{2}$ uptake throughout most of the green season compared to EG canopies (effect of canopy type: NEE $-P<0.001$, $\left.F_{1,203}=342.69\right)$. Also, SDOT had greater net $\mathrm{CO}_{2}$ uptake compared to IMVT throughout most of the green season (effect of site: NEE $-P<0.001, F_{1,203}=52.19$ ).

Because DS canopies had higher LAI values during both green and peak seasons, and longer peak seasons, DS canopies took up about twice as much $\mathrm{C}(P<0.001)$ during their green season (an estimated additional $113 \mathrm{~g} \mathrm{C} \mathrm{m}^{-2}$ season $^{-1}$ ), and nearly three times the amount of $C(P<0.001)$ during their peak season (an estimated additional $101 \mathrm{~g} \mathrm{C} \mathrm{m}^{-2}$ season $^{-1}$ ) compared to EG canopies (Table 2). SDOT took up more total NEE compared to IMVT during both the green and peak seasons (effect of site: green season NEE $P<0.05, \quad F_{1,15}=8.22$; peak season NEE $-P<0.01$, $F_{1,15}=10.07$ ).

To tease out the effect of different LAI across vegetation communities, and further examine the effect of changing season length, we estimated green and peak season NEE for each community type under changing 
Table 1 Canopy phenology metrics \pm 1 standard error of the mean (SEM) determined from piecewise linear regression modeling and threshold analysis

\begin{tabular}{|c|c|c|c|c|c|c|}
\hline Phenological parameter & DS & EG & Difference & $P$ & $F$ & $\mathrm{df}$ \\
\hline \multicolumn{7}{|c|}{ (a) Average canopy phenology stage date } \\
\hline \multicolumn{7}{|l|}{ Onset of greening } \\
\hline Piecewise & $163 \pm 1$ & $161 \pm 1$ & $2^{*}$ & $<0.05$ & 4.97 & 1,15 \\
\hline Threshold & $168 \pm 2$ & $168 \pm 2$ & 0 & ns & & \\
\hline \multicolumn{7}{|l|}{ Onset of peak green } \\
\hline Piecewise & $182 \pm 2$ & $195 \pm 3$ & $-13^{*}$ & $<0.001$ & 16.93 & 1,15 \\
\hline Threshold & $182 \pm 3$ & $193 \pm 2$ & $-11^{*}$ & $<0.001$ & 18.47 & 1,15 \\
\hline \multicolumn{7}{|l|}{ Onset of senescence } \\
\hline Piecewise & $226 \pm 1$ & $229 \pm 2$ & -3 & ns & & \\
\hline Threshold & $227 \pm 2$ & $230 \pm 2$ & -3 & ns & & \\
\hline \multicolumn{7}{|c|}{ (b) Average canopy phenology parameter } \\
\hline \multicolumn{7}{|l|}{ Growing season length } \\
\hline Piecewise & $85 \pm 1$ & $87 \pm 1$ & -2 & ns & & \\
\hline Threshold & $80 \pm 2$ & $80 \pm 2$ & 0 & ns & & \\
\hline \multicolumn{7}{|l|}{ Peak season length } \\
\hline Piecewise & $44 \pm 3$ & $34 \pm 4$ & $10^{*}$ & $<0.05$ & 7.39 & 1,15 \\
\hline Threshold & $45 \pm 4$ & $37 \pm 3$ & $8^{*}$ & $<0.05$ & 4.91 & 1,15 \\
\hline \multicolumn{7}{|l|}{ Rate of green-up } \\
\hline Piecewise & $0.018 \pm 0.003$ & $0.007 \pm 0.002$ & $0.011^{*}$ & $<0.001$ & 16.94 & 1,15 \\
\hline Threshold & $0.016 \pm 0.003$ & $0.005 \pm 0.001$ & $0.010^{*}$ & $<0.01$ & 15.46 & 1,15 \\
\hline
\end{tabular}

(a) Dates of canopy-level phenological parameters [day of year (DOY)]. Differences indicate number of days earlier (minus sign) or later (no sign) deciduous shrub (DS) canopies reached each stage compared to evergreen/graminoid (EG) canopies. (b) Lengths (number of days) of growing and peak seasons, and canopy rates of green-up (slopes). Differences indicate shorter (minus sign) or longer (no sign) seasons, and faster rates of green-up for DS compared to EG canopies. Asterisks (*) indicate dates or values in a row were significantly different from one another, and 'ns' indicates no significant difference. $P$-values $(P), F$-ratios $(F)$, and degrees of freedom (df) are given for significant main effects of mean comparisons of DS and EG canopy values in each row.

season lengths (Table 3). Increasing the green season length by 5 days increased $C$ uptake for DS and EG canopies by $3 \%$ and $4 \%$, respectively (Table $3 a$ ). Extending the peak season by 10 days increased $C$ uptake by $84 \%(P<0.001)$ for DS canopies (an estimated additional $71 \mathrm{~g} \mathrm{C} \mathrm{m}^{-2}$ season $^{-1}$ ) and by $64 \%$ $(P<0.05)$ for EG canopies (an estimated additional $30 \mathrm{~g} \mathrm{C} \mathrm{m}^{-2}$ season $^{-1}$ ) (Table $3 \mathrm{~b}$ ).

To further examine the effect of increasing deciduous shrub cover on NEE, we evaluated the relationship between percent deciduous shrub cover and seasonal NEE across all quadrats (Fig. $3 g$, h). We found that both green and peak season NEE were significantly greater when percent deciduous shrub cover was greater (green season NEE $-R^{2}=0.76, P<0.001$, $F_{1,16}=51.28$; peak season $\mathrm{NEE}-R^{2}=0.85, P<0.001$, $\left.F_{1,16}=87.31\right)$.

\section{Model sensitivity analysis}

To assess the sensitivity of total peak season net ecosystem exchange (peak NEE) to changes in air $T$, PAR, LAI, and the onset date of the peak season, we varied individual model parameters by stepwise percentages (Fig. 5). On average, peak NEE was most sensitive to changes in PAR and the timing of the onset of the peak season, and least sensitive to changes in LAI. For instance, if considering average percent change (i.e., across both canopy types), a $20 \%$ increase in LAI increased peak NEE by $12 \%$, whereas a $20 \%$ increase in the onset of the peak season or PAR increased peak NEE by $33 \%$ and $21 \%$, respectively. The effect changing air $T$ had on peak NEE was relatively similar in magnitude of effect, but opposite in directional effect compared to other model parameters, where an increase in air $T$ of $20 \%$ decreased peak NEE by $19 \%$.

Decreases in PAR led to larger magnitude changes compared to the same percentage increases in PAR. As this was not the case for the onset of the peak season, peak NEE was, on average, most sensitive to the earlier onset of the peak season. For instance, if considering average percent change across both canopy types, a $30 \%$ increase in PAR increased peak NEE by $32 \%$, while a $30 \%$ decrease in PAR decreased peak NEE by $47 \%$. On the other hand, a 30\% earlier (or later) onset of the peak season led to an increase (or decrease) in peak NEE of $46 \%$. 

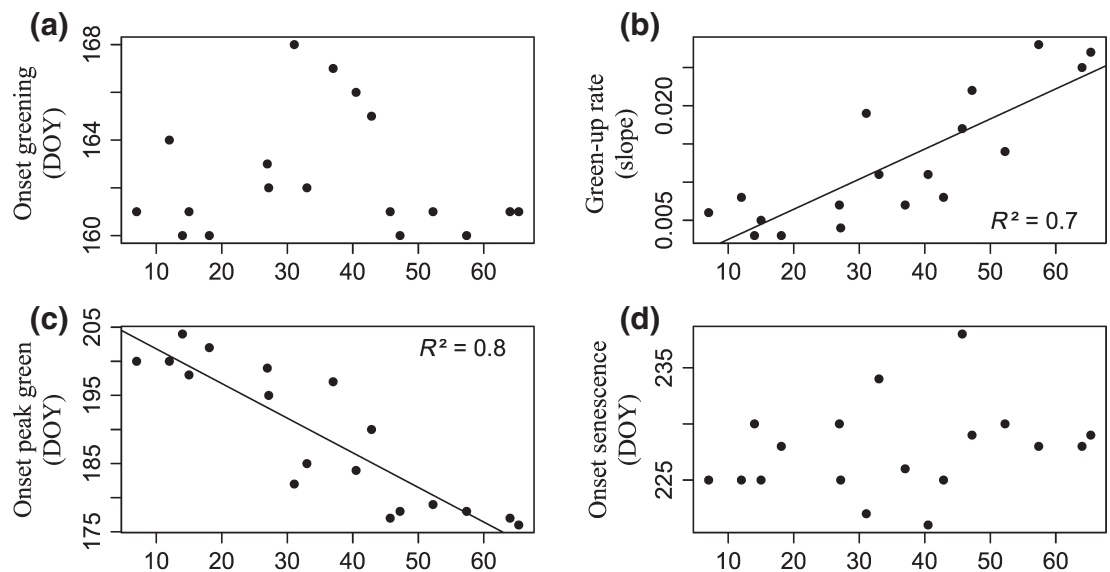

(d)
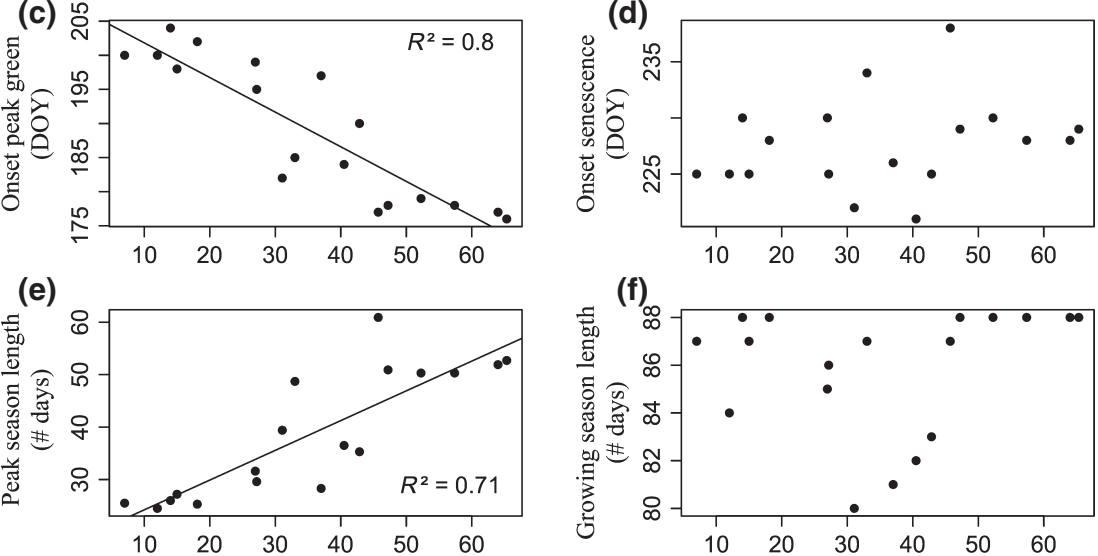

(g)

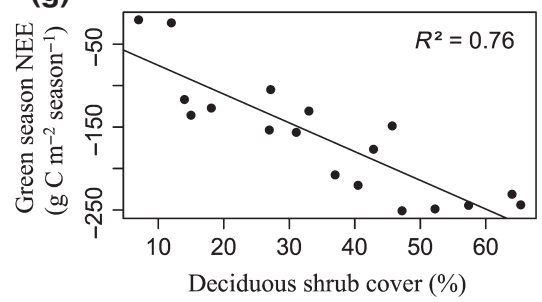

(h)

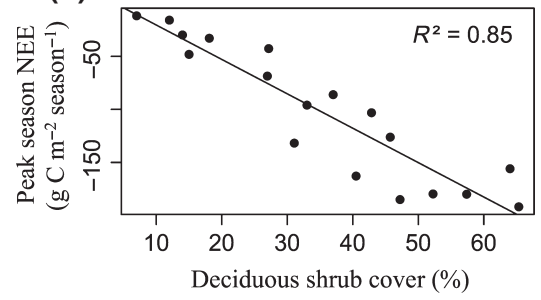

Fig. 3 Relationships between percent deciduous shrub cover of canopies along all transects $(n=18)$ and (a) onset of greening, (b) rate of green-up, (c) onset of peak green, (d) onset of senescence, (e) length of the peak green season, (f) length of the growing season; and modeled estimates of total net ecosystem exchange (NEE) in grams of carbon (C) $\mathrm{m}^{-2}$ season ${ }^{-1}$ during $(\mathrm{g})$ the green season and (h) the peak season. Canopy metrics were determined using piecewise regression modeling.

Although DS and EG canopies' peak NEE was similarly sensitive to changes in PAR, air $T$, and onset of the peak season, DS canopies were much less sensitive to changes in LAI compared to EG canopies (Fig. 5). For instance, increasing LAI by $30 \%$ increased peak NEE for DS canopies by $6 \%$ and for EG canopies by $28 \%$. And decreasing LAI by $30 \%$ decreased peak NEE for DS canopies by $21 \%$ and for EG canopies by $38 \%$.

\section{Discussion}

\section{Deciduous shrubs lengthen the period of peak canopy} greenness

The main findings of this study suggest that in the Alaskan arctic tundra, greater deciduous shrub abundance causes a net lengthening of the period of peak tundra greenness by advancing the onset of peak leaf out. A number of studies have shown differences in canopy phenology among different tundra types (e.g.,
Jia et al., 2004; Narasimhan \& Stow, 2010), as well as differences between tundra vegetation communities in net carbon flux (e.g., Shaver et al., 2007; Street et al., 2007). However, to our knowledge, this is the first study to combine both in unmanipulated, naturally occurring deciduous shrub and evergreen/graminoid tundra, thereby contributing new insight into the effect of deciduous shrub cover on the length of the peak season (e.g., the period of maximum tundra greenness).

We found that deciduous shrub canopies had an accelerated rate of green-up and reached the onset of peak green 13 days earlier compared to evergreen/ graminoid canopies. Because deciduous shrub canopies reached the onset of senescence only 3 days earlier, the period of peak tundra greenness (from the onset of peak green to the onset of senescence) was 10 days longer for deciduous shrub canopies compared to evergreen/graminoid canopies. However, because deciduous shrub and evergreen/graminoid canopies began greening at similar times and ended senescence at the 
(a)

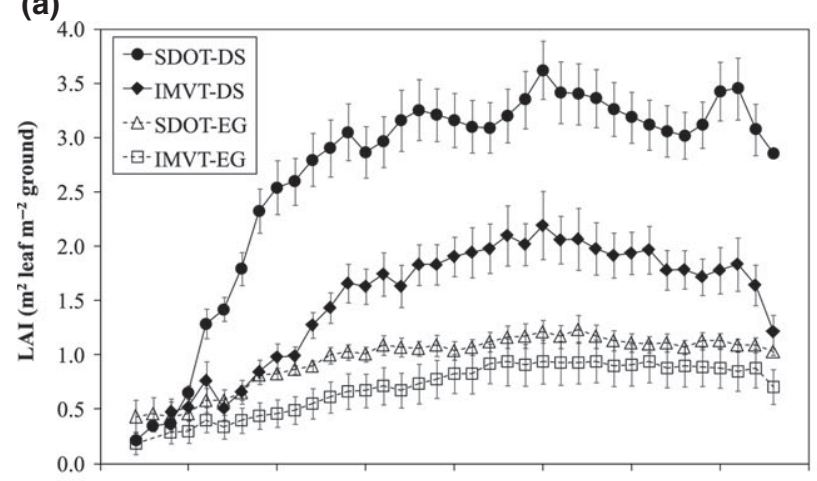

(c)

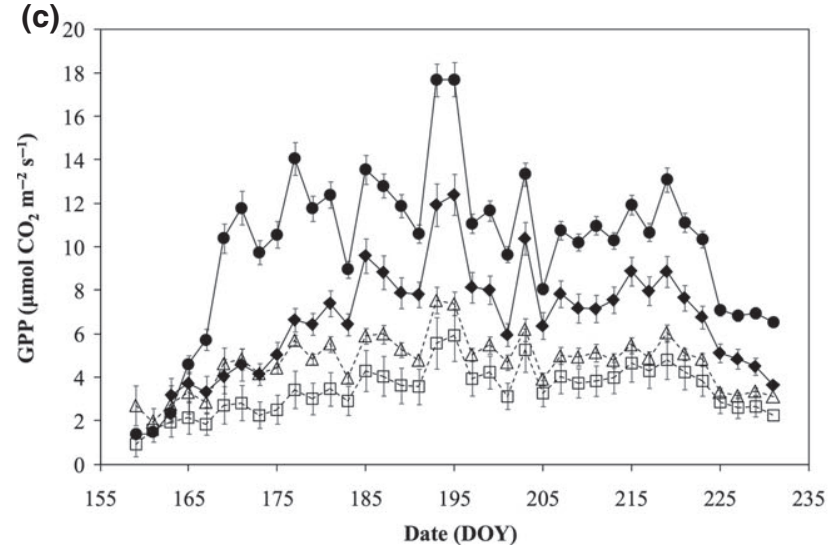

(b)

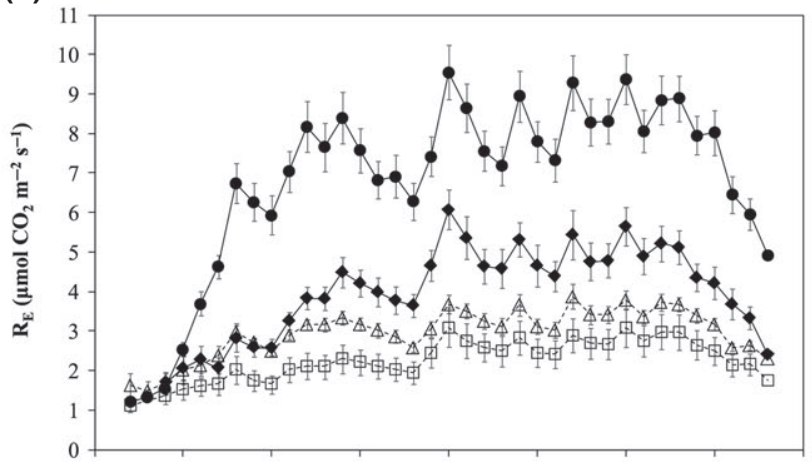

(d)

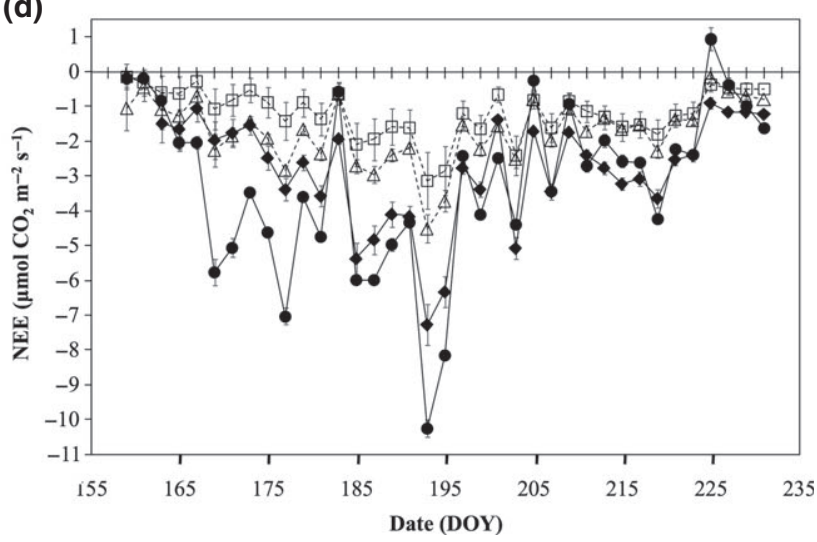

Fig. 4 Modeled estimates of 2-day averages of seasonal (a) leaf area index (LAI), (b) respiration $\left(R_{\mathrm{E}}\right)$, (c) gross primary production (GPP), and (d) net ecosystem exchange (NEE) for deciduous shrub (DS, filled symbols) and evergreen/graminoid (EG, open symbols) canopies at each of the two study sites. Error bars represent 1 standard error of the mean (SEM).

Table 2 Modeled estimates of integrated total net ecosystem exchange (NEE) in grams of carbon (C) $\mathrm{m}^{-2}$ season $^{-1} \pm 1 \mathrm{standard}$ error of the mean (SEM) for green and peak seasons, as determined by piecewise linear regression modeling

\begin{tabular}{|c|c|c|c|c|c|c|}
\hline & DS & EG & Difference (\% additional) & $P$ & $F$ & df \\
\hline Green season NEE $\left(\mathrm{g} \mathrm{C} \mathrm{m}^{-2}\right.$ season $\left.^{-1}\right)$ & $-220 \pm 11$ & $-107 \pm 17$ & $113(106 \%) *$ & $<0.001$ & 45.47 & 1,15 \\
\hline Peak season NEE $\left(\mathrm{g} \mathrm{C} \mathrm{m}^{-2}\right.$ season $\left.^{-1}\right)$ & $-153 \pm 13$ & $-52 \pm 13$ & $101(192 \%)^{*}$ & $<0.001$ & 49.36 & 1,15 \\
\hline
\end{tabular}

Differences indicate amount of additional grams C uptake for deciduous shrub (DS) compared to evergreen/graminoid (EG) canopies; percentages indicate the percent additional carbon gain for DS relative to EG canopies. Asterisks $\left(^{*}\right)$ indicate values in a row were significantly different from one another. $P$-values $(P), F$-ratios $(F)$, and degrees of freedom $(\mathrm{df})$ are given for significant main effects of mean comparisons of DS and EG canopy NEE values in each row.

same time, greater deciduous shrub dominance did not lengthen the overall growing season (from the onset of greening to the end of senescence). These results suggest that the ongoing increase in deciduous shrub dominance in the arctic tundra (Forbes et al., 2010; Myers-Smith et al., 2011) may be contributing to the concurrent satellite-detected trend toward an earlier onset of the peak green season (Goetz et al., 2005; Jia et al., 2009; Tagesson et al., 2012), but not necessarily to observed lengthening of the entire growing season (Zhou et al., 2001; Jeong et al., 2011; Zeng et al., 2011). Longer overall growing seasons are more likely related to increases in air temperature (Hollister et al., 2005; Xu et al., 2013) and reductions in snow cover duration (Stow et al., 2004; Wipf, 2010) associated with climate change, which cause an earlier onset of greening and/or a later end of senescence (Tucker et al., 2001; Jia et al., 2004).

\section{Deciduous shrubs lengthen the period of maximum canopy carbon uptake}

We found that due to the combined effects of higher leaf area and a longer peak season, deciduous shrub canopies took up nearly three times the amount (an 
Table 3 Modeled estimates of integrated total net ecosystem exchange (NEE) in grams of carbon (C) $\mathrm{m}^{-2}$ season $^{-1} \pm 1$ standard error of the mean (SEM) for deciduous shrub (DS) or evergreen/graminoid (EG) canopies, as determined by piecewise linear regression modeling

\begin{tabular}{|c|c|c|c|c|c|c|}
\hline (a) & $\begin{array}{l}\text { DS green season } \\
\text { (63 days) }\end{array}$ & $\begin{array}{l}\text { EG green season } \\
\text { (68 days) }\end{array}$ & $\begin{array}{l}\text { Difference } \\
\text { (\% additional) }\end{array}$ & $P$ & $F$ & df \\
\hline DS NEE $\left(\mathrm{g} \mathrm{C} \mathrm{m}^{-2}\right.$ season $\left.^{-1}\right)$ & $-221 \pm 10$ & $-228 \pm 10$ & $7(3 \%)$ & ns & & \\
\hline EG NEE $\left(\mathrm{g} \mathrm{C} \mathrm{m}^{-2}\right.$ season $\left.^{-1}\right)$ & $-103 \pm 16$ & $-107 \pm 16$ & $4(4 \%)$ & ns & & \\
\hline (b) & $\begin{array}{l}\text { DS peak season } \\
\text { ( } 44 \text { days) }\end{array}$ & $\begin{array}{l}\text { EG peak season } \\
\text { (34 days) }\end{array}$ & & & & \\
\hline DS NEE $\left(\mathrm{g} \mathrm{C} \mathrm{m}^{-2}\right.$ season $\left.^{-1}\right)$ & $-156 \pm 5$ & $-85 \pm 4$ & $71(84 \%) *$ & $<0.001$ & 114.84 & 1,15 \\
\hline EG NEE $\left(\mathrm{g} \mathrm{C} \mathrm{m}^{-2}\right.$ season $\left.^{-1}\right)$ & $-77 \pm 12$ & $-47 \pm 7$ & $30(64 \%) *$ & $<0.05$ & 5.58 & 1,15 \\
\hline
\end{tabular}

(a) Comparing total NEE under two green season length scenarios: (1) DS green season (day of year, DOY 163-226, 63 days) and (2) EG green season (DOY 161-229, 68 days). Differences indicate amount of additional grams C uptake during the longer green season (i.e., 5 days longer). Percentages indicate the percent additional carbon uptake during the longer green season. (b) Comparing total NEE under two peak season length scenarios: (1) DS peak season (DOY 182-226, 44 days) and (2) EG peak season (DOY 195-229, 34 days). Differences indicate amount of additional grams $C$ uptake during the longer peak season (i.e., 10 days longer). Percentages indicate the percent additional carbon uptake during the longer peak season scenario. Asterisks $(*)$ indicate values in a row were significantly different from one another, and 'ns' indicates no significant difference. $P$-values $(P), F$-ratios $(F)$, and degrees of freedom (df) are given for significant main effects of mean comparisons of NEE values in each row.

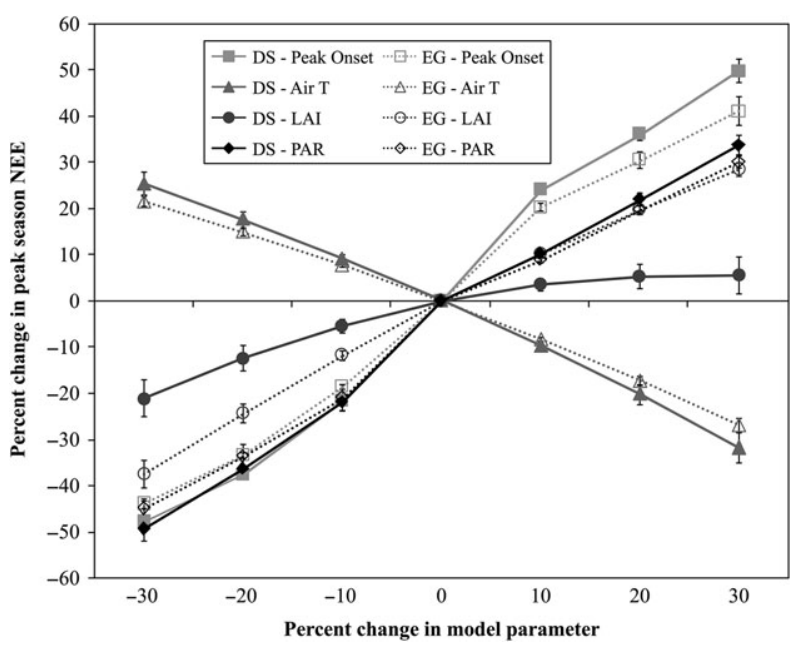

Fig. 5 Sensitivity of modeled estimates of total peak season net ecosystem exchange (NEE) for deciduous shrub (DS) and evergreen/graminoid (EG) canopies to changes in four NEE model parameters: irradiance (PAR), air temperature (Air T), leaf area (LAI), and onset date of the peak season (Peak Onset). Percent differences from original values of PAR, Air T, and LAI and a baseline peak onset date of day of year 189 are shown on the $x$-axis. Percent change in total peak green season NEE with changes in model parameters is on the $y$-axis. The percent changes in model parameters were applied equally across DS and EG canopies. Error bars represent 1 standard error of the mean (SEM).

estimated additional $101 \mathrm{~g} \mathrm{C} \mathrm{m}^{-2}$ season $^{-1}$ ) of carbon compared to evergreen/graminoid canopies. However, we also found that a 10-day extension of the peak season alone nearly doubled the net carbon uptake in deciduous shrub and canopies, increasing uptake by an estimated $71 \mathrm{~g} \mathrm{C} \mathrm{m}^{-2}$ season $^{-1}$. Thus, while a portion $(\sim 29 \%)$ of the additional carbon uptake by deciduous shrub communities during the period of peak greenness was due to greater leaf area, a significant portion $(\sim 71 \%)$ was due to the extended duration of the peak season exhibited by deciduous shrub communities compared to evergreen/graminoid communities. Our results are supported by previous work showing that the carbon gain potential of the tundra is enhanced when the arctic peak season is extended (Tagesson et al., 2012). Our findings on the effect deciduous shrub abundance has on the length of the peak season are important as carbon uptake is at its maximum for tundra communities during the peak season (Richardson et al., 2009; Ueyama et al., 2013; Mbufong et al., 2014).

Our results suggest that greater deciduous shrub abundance increases carbon uptake not only due to greater leaf area, but also due to an extension of the period of peak greenness, which extends the period of maximum carbon uptake. Thus, an extended period of peak greenness with increasing deciduous shrub abundance may increase tundra carbon gain. These findings provide valuable insight into how changes in vegetation community composition may be driving satellitedetected changes in vegetation phenology and how this, in turn, may affect tundra carbon flux. Future high-resolution field, space, and/or airborne remote sensing studies could help support the findings of this study at larger scales and reduce uncertainties in 
modeling future changes in vegetation phenology (Steltzer \& Post, 2009) and associated carbon budgeting (Nemani et al., 2002; Jeong et al., 2012).

\section{Modeling tundra carbon exchange}

Our sensitivity analysis suggests that the magnitude of change in total peak season NEE is most sensitive to changes in PAR and the timing of the onset of the peak season, and least sensitive to changes in LAI. Peak NEE was most sensitive to the earlier onset of the peak season. The sensitivity of peak NEE to changes in the onset of the peak season is supported by the main finding of our study, where we found that the earlier onset of the peak season significantly increased carbon gain in both deciduous shrub and evergreen/graminoid tundra. The sensitivity analysis suggests that the effect deciduous shrub cover has on the length of the peak season may be just as, if not more, important than the effect deciduous shrub cover has on leaf area when considering tundra carbon gain potential.

The sensitivity of peak NEE to changes in PAR, such as might be the result of increased cloudiness, suggests that changes in insolation may have large effects on peak season NEE. Light-attenuation studies in the Alaskan arctic tundra have shown that reduced light (representative of increased cloud cover) may decrease photosynthesis (Chapin \& Shaver, 1996), nutrient uptake, and plant biomass (Chapin et al., 1995). This may prove important given that satellite records suggest summer cloud cover has increased in Alaska (Chapin et al., 2005) and the pan-Arctic (Wang \& Key, 2003) over the last several decades.

Increases in PAR and LAI, as well as the earlier onset of the peak season, increased carbon uptake, while increases in air $T$ decreased carbon uptake, since carbon loss from respiration increased with increasing air $T$, while GPP was unaffected. This sensitivity of respiration to changes in air $T$ could prove important given that air temperatures are predicted to continue rising in the arctic tundra (IPCC, 2013). Increasing air temperatures could increase respiration (Cahoon et al., 2012; Heskel et al., 2013), and potentially offset increases in carbon uptake due to longer peak green seasons and greater leaf area associated with increasing deciduous shrub cover (Belshe et al., 2013).

We found that deciduous shrub canopy NEE was less sensitive to changes in LAI than evergreen/graminoid canopy NEE. Although higher LAI during peak season increased the daily rate of carbon gain in both canopy types, earlier seasons had a critical impact on NEE by increasing the number of days early in the peak season when carbon gain was greater than carbon loss. Thus, in deciduous shrub tundra, which already has a much higher LAI compared to evergreen/graminoid tundra, an earlier onset of the peak season increased carbon uptake much more substantially than proportional increases in LAI.

It is important to note that by focusing on the growing season, this study examined the influence of deciduous shrub cover on net carbon exchange during only the snow-free season, but respiratory carbon flux during the winter may also be altered by increasing deciduous shrub cover. Some studies suggest that increasing deciduous shrub cover may enhance carbon loss in winter through changes in snow cover dynamics and winter soil temperature regimes (Walker et al., 1999; Schimel et al., 2004) that influence heterotrophic respiration. Further, it has been suggested that evergreens may be photosynthetically active under the snow in spring (Starr \& Oberbauer, 2003), which may enhance annual carbon uptake where evergreen species are abundant. Also, although the NEE model has shown great accuracy in estimating entire ecosystem carbon flux across a variety of tundra landscapes (Shaver et al., 2007; Loranty et al., 2010; Rastetter et al., 2010), a portion of the unexplained variance may be due in part to respiration from shallow soil depths, or differences in plant species composition not incorporated into the model (Shaver et al., 2013). While it is not possible to predict with $100 \%$ certainty what the future of net carbon flux will be for arctic tundra, our results suggest that increasing deciduous shrub cover significantly increases the carbon uptake potential of the tundra by both increasing leaf area and extending the length of the peak season.

\section{Acknowledgements}

We thank Rick Shory and Geneva Chong for help with equipment and data analysis. We thank Gus Shaver for advisement; and Jesse Krause, Jessica Gersony, Heather Greaves, and TeamBird 2013 for field assistance. We also thank the Institute of Arctic Biology/Toolik Field Station (University of Alaska, Fairbanks) for support. This project has been funded by grants from NSF's Office of Polar Programs (ARC 0908444 to NT Boelman; 0908602 to L Gough; 0902030 to H Steltzer) and a Climate Center grant (Columbia University: UR00801-07 60437 to KL Griffin).

\section{References}

ACIA (Arctic Climate Impact Assessment) (2004) Impacts of a Warming Arctic. Cambridge University Press, Cambridge, UK and New York, NY, USA.

AMAP (Arctic Monitoring and Assessment Programme) (2012) SWIPA overview report. In: Arctic Climate Issues 2011: Changes in Arctic Snow, Water, Ice and Permafrost (eds. Shearer R, Wrona F, Klint M, Larsen H, Skovgaard O, Mahonen O, Jensson H, Dovle P, Tsaturov Y, Lundeberg T, Armstrong T, Solbakken J-I), pp. 30-40. Oslo, Norway.

Baret F, Guyot G (1991) Potentials and limits of vegetation indices for LAI and APAR assessment. Remote Sensing of Environment, 35, 161-173.

Barichivich J, Briffa KR, Myneni RB et al. (2013) Large-scale variations in the vegetation growing season and annual cycles of atmospheric $\mathrm{CO}_{2}$ at high northern latitudes from 1950 to 2011. Global Change Biology, 19, 3167-3183. 
Belshe EF, Schuur EAG, Bolker BM (2013) Tundra ecosystems observed to be $\mathrm{CO}_{2}$ sources due to differential amplification of the carbon cycle. Ecology Letters, 16, 1316-1324.

de Beurs KM, Henebry GM (2010) Spatio-temporal statistical methods for modeling land surface phenology. In: Phenological Research (eds Hudson IL, Keatley MR), pp 177-208. Springer, Dordrecht, Netherlands.

Bunn AG, Goetz SJ, Kimball JS, Zhang K (2007) Northern high-latitude ecosystems respond to climate change. Eos, 88, 333-335.

Cahoon SMP, Sullivan PF, Shaver GR, Welker JM, Post E (2012) Interactions among shrub cover and the soil microclimate may determine future Arctic carbon budgets. Ecology Letters, 15, 1415-1422.

Chandola V, Hui D, Gu L, Bhaduri B, Vatsavai RR (2010) Using time series segmentation for deriving vegetation phenology indices from MODIS NDVI data. In: Proceedings of the 2010 IEEE International Conference on Data Mining Workshops, pp. 202-208.

Chapin FS III, Shaver GR (1996) Physiological and growth responses of arctic plants to a field experiment simulating climate change. Ecology, 77, 822-840.

Chapin FS III, Shaver GR, Giblin AE, Nadelhoffer KJ, Laundre JA (1995) Responses of arctic tundra to experimental and observed changes in climate. Ecology, 76, 694 711.

Chapin FS III, Sturm M, Serreze MC et al. (2005) Role of land-surface changes in arctic summer warming. Science, 310, 657-660.

Cleveland WS (1979) Robust locally weighted regression and smoothing scatterplots. Journal of the American Statistical Association, 74, 829-836.

Cleveland WS, Loader CR (1996) Smoothing by local regression models. In: Statistical Theory and Computational Aspects of Smoothing (eds Hardle W, Schimek MG), pp. 10-49. Physica-Verlag, Heidelberg.

Cornelissen JHC, Callaghan TV, Alatalo JM et al. (2001) Global change and arctic ecosystems: is lichen decline a function of increases in vascular plant biomass? Journal of Ecology, 89, 984-994.

Delbart N, Picard G (2007) Modeling the date of leaf appearance in low-arctic tundra. Global Change Biology, 13, 2551-2562.

Elmendorf SC, Henry GHR, Hollister RD et al. (2012) Plot-scale evidence of tundra vegetation change and links to recent summer warming. Nature Climate Change, 2 453-457.

Euskirchen ES, McGuire AD, Kicklighter DW et al. (2006) Importance of recent shifts in soil thermal dynamics on growing season length, productivity, and carbon sequestration in terrestrial high-latitude ecosystems. Global Change Biology, 12, 731-750.

Forbes BC, Fauria MM, Zetterberg P (2010) Russian Arctic warming and 'greening' are closely tracked by tundra shrub willows. Global Change Biology, 16, $1542-1554$

Fraser RH, Olthof I, Carriere M, Deschamps A, Pouliot D (2011) Detecting long-term changes to vegetation in northern Canada using the Landsat satellite image archive. Environmental Research Letters, 6, 045502.

Goetz SJ, Bunn AG, Fiske GJ, Houghton RA, Woodwell GM (2005) Satelliteobserved trends across Boreal North America associated with climate and fire disturbance. Proceedings of the National Academy of Science, USA, 102, 1352113525 .

Goetz SJ, Epstein HE, Alcaraz D et al. (2010) Recent changes in Arctic vegetation: satellite observations and simulation model predictions. In: Arctic Land Cover and Land Use in a Changing Climate (ed. Gutman G), Chapter 2. Springer-Verlag, Amsterdam, the Netherlands.

Heskel MA, Betterman D, Atkin OK, Turnbull MH, Griffin KL (2013) Seasonality of foliar respiration in two dominant plant species from the arctic tundra: response to long-term warming and short-term temperature variability. Functional Plant Biology, 41, 287-300.

Hinzman LD, Bettez ND, Bolton WR et al. (2005) Evidence and implications of recent climate change in northern Alaska and other arctic regions. Climate Change, 72, 251-298.

Hollister RD, Webber PJ, Bay C (2005) Plant response to temperature in northern Alaska: implications for predicting vegetation change. Ecology, 86, 1562-1570.

Huemmrich KF, Black TA, Jarvis PG, McCaughty JH, Hall FG (1999) High temporal resolution NDVI phenology from micrometeorological radiation sensors. Journal of Geophysical Research, 104, 27935-27944.

IPCC (Intergovernmental Panel on Climate Change) (2013) Fifth assessment report. In: Climate Change 2013 - Working Group I: The Physical Science Basis (eds Stocker TF, Qin D, Plattner G-K, Tignor M, Allen SK, Boschung J, Nauels A, Xia Y, Bex V, Midgley PM), pp. 130-194; 1257-1258. Cambridge University Press, Cambridge, UK.

Jacoby MG (2000) Loess: a nonparametric, graphical tool for depicting relationships between variables. Electoral Studies, 19, 577-613.
Jeong SJ, Ho CH, Gim HJ, Brown ME (2011) Phenology shifts at start vs. end of growing season in temperate vegetation over the Northern Hemisphere for the period 1982-2008. Global Change Biology, 17, 2385-2399.

Jeong SJ, Medvigy D, Shevliakova E, Malyshev S (2012) Uncertainties in terrestrial carbon budgets related to spring phenology. Journal of Geophysical Research: Biogeosciences (2005-2012), 117, G1.

Jia GJ, Epstein HE, Walker DA (2003) Greening of arctic Alaska, 1981-2001. Geophysical Research Letters, 30, 2067

Jia GJ, Epstein HE, Walker DA (2004) Controls over intra-seasonal dynamics of AVHRR NDVI for the arctic tundra in northern Alaska. International Journal of Remote Sensing, 25, 1547-1564.

Jia GJ, Epstein HE, Walker DA (2009) Vegetation greening in the Canadian arctic related to decadal warming. Journal of Environmental Monitoring, 11, 2231-2238.

Johnson LC, Shaver GR, Cades DH et al. (2000) Plant carbon-nutrient interactions control $\mathrm{CO}_{2}$ exchange in Alaskan wet-sedge tundra ecosystems. Ecology, 81, 453469.

Kikuzawa K (1995) Leaf phenology as an optimal strategy for carbon gain in plants. Canadian Journal of Botany, 73, 158-163.

Klosterman ST, Hufkens K, Gray JM et al. (2014) Evaluating remote sensing of deciduous forest phenology at multiple spatial scales using PhenoCam imagery. Biogeosciences Discussions, 11, 2305-2342.

Kogan FN (1995) Droughts of the late 1980's in the United States as derived from NOAA polar-orbiting satellite data. Bulletin of the American Meteorological Society, 76, 655-668.

van Leeuwen WJ, Orr BJ, Marsh SE, Herrmann SM (2006) Multi-sensor NDVI data continuity: uncertainties and implications for vegetation monitoring applications. Remote Sensing of Environment, 100, 67-81.

Loranty MM, Goetz SJ, Rastetter EB, Rocha AV, Shaver GR, Humphreys ER, Lafleur PM (2010) Scaling an instantaneous model of tundra NEE to the Arctic landscape. Ecosystems, 14, 76-93.

Mbufong HN, Lund M, Aurela M et al. (2014) Assessing the spatial variability in peak season $\mathrm{CO}_{2}$ exchange characteristics across the Arctic tundra using a light response curve parameterization. Biogeosciences Discussions, 11, 6419-6460.

McBean G, Alekseev G, Chen D et al. (2006) Arctic climate impact assessment. In: Scientific Report: Arctic Climate: Past and Present (eds Symon C, Arris L, Heal B), pp. 22-55. Cambridge University Press, Cambridge, UK.

Muggeo VMR (2003) Estimating regression models with unknown break-points. Statistics in Medicine, 22, 3055-3071.

Muggeo VMR (2008) segmented: an R package to fit regression models with brokenline relationships. $R$ News, 8/1, 20-25. Available at: http://cran.r-project.org/doc/ Rnews/ (accessed 6 August 2014).

Myers-Smith IH, Forbes BC, Wilmking M et al. (2011) Shrub expansion in tundra ecosystems: dynamics, impacts and research priorities. Environmental Research Letters, 6, 045509 .

Myneni RB, Keeling D, Tucker CJ, Asrar G, Nemani RR (1997) Increased plant growth in the northern high latitudes from 1981-1991. Nature, 386, 698-702.

Narasimhan R, Stow D (2010) Daily MODIS products for analyzing early season vegetation dynamics across the North Slope of Alaska. Remote Sensing of Environment $114,1251-1262$.

Nemani R, White M, Thornton P, Nishida K, Reddy S, Jenkins J, Running S (2002) Recent trends in hydrologic balance have enhanced the terrestrial carbon sink in the United States. Geophysical Research Letters, 29, 1468-1471.

Oberbauer SF, Starr G, Pop EW (1998) Effects of extended growing season and soil warming on carbon dioxide and methane exchange of tussock tundra in Alaska. Journal of Geophysical Research, 103, 29075-29082.

Olthof I, Pouliot D, Latifovic R, Chen W (2008) Recent (1986-2006) vegetation-specific NDVI trends in northern Canada from satellite data. Arctic, 61, 381-394.

Overland J, Key J, Kim BM et al. (2012) Air temperature, atmospheric circulation and clouds. Arctic Report Card: Update for 2012. Available at: http://www.arctic noaa.gov/report12/temperature_clouds.html. (accessed 12 January 2014).

Pau S, Wolkovich EM, Cook BI et al. (2011) Predicting phenology by integrating ecology, evolution and climate science. Global Change Biology, 17, 3633-3643.

Pearson RG, Phillips SJ, Loranty MM, Beck PSA, Damoulas T, Knight SJ, Goetz SJ (2013) Shifts in Arctic vegetation and associated feedbacks under climate change. Nature Climate Change, 3, 673-677.

Piao S, Wang X, Ciais P, Zhu B, Wang TAO, Liu JIE (2011) Changes in satellitederived vegetation growth trend in temperate and boreal Eurasia from 1982 to 2006. Global Change Biology, 17, 3228-3239.

R Core Team (2014) R: A Language and Environment for Statistical Computing. R Foundation for Statistical Computing, Vienna, Austria. Available at: http://www.Rproject.org/ (accessed 2 August 2014). 
Rastetter EB, King AW, Cosby BJ, Hornberger GM, O'Neill RV, Hobbie JE (1992) Aggregating fine-scale ecological knowledge to model coarser-scale attributes of ecosystems. Ecological Applications, 2, 55-70.

Rastetter EB, Williams M, Griffin KL et al. (2010) Processing arctic eddy-flux data using simple carbon-exchange model embedded in the ensemble Kalman filter. Ecological Applications, 20, 1285-1301.

Richardson AD, Hollinger DY, Dail DB, Lee JT, Munger JW, O'Keefe J (2009) Influence of spring phenology on seasonal and annual carbon balance in two contrasting New England forests. Tree Physiology, 29, 321-331.

Schimel JP, Bilbrough C, Welker JM (2004) Increased snow depth affects microbial activity and nitrogen mineralization in two arctic tundra communities. Soil Biology and Biochemistry, 36, 217-227.

Serreze MC, Francis JA (2006) The arctic on the fast track of change. Weather, 61, 6569.

Shaver GR, Street LE, Rastetter EB, van Wijk MT, Williams M (2007) Functional convergence in regulation of net $\mathrm{CO}_{2}$ flux in heterogeneous tundra landscapes in Alaska and Sweden. Journal of Ecology, 95, 802-817.

Shaver GR, Rastetter EB, Salmon V et al. (2013) Pan-Arctic modeling of net ecosystem exchange of $\mathrm{CO}_{2}$. Philosophical Transactions of the Royal Society B: Biological Sciences, $368,20120485$.

Shory R (2014) rickshory/NDVI-modules: for processing logged spectral data into NDVI; x-platform using wxPython. On GitHub, Inc. Available at: http://github.com/rickshory/NDVI-modules (accessed 28 October 2014).

Starr G, Oberbauer SF (2003) Photosynthesis of arctic evergreens under snow: implications for tundra ecosystem carbon balance. Ecology, 84, 1415-1420.

Steltzer H, Post E (2009) Seasons and life cycles. Science, 324, 886-887.

Steltzer H, Welker JM (2006) Modeling the effects of photosynthetic vegetation properties on the NDVI-LAI relationship. Ecology, 87, 2765-2772.

Stow DA, Hope A, McGuire D et al. (2004) Remote sensing of vegetation and land-cover change in arctic tundra ecosystems. Remote Sensing of Environment, 89, 281-308.

Street LE, Shaver GR, Williams M, van Wilk MT (2007) What is the relationship between changes in leaf area and changes in photosynthetic $\mathrm{CO}_{2}$ flux in arctic ecosystems? Journal of Ecology, 95, 139-150.

Sturm M, McFadden JP, Liston GE, Chapin FS, Racine CH, Holmgren J (2001a) Snowshrub interactions in arctic tundra: a hypothesis with climate implications. Journal of Climate, 14, 336-344.

Sturm M, Racine CR, Tape K (2001b) Increasing shrub abundance in the Arctic. Nature, 411, 546-547.

Sturm M, Schimel J, Michaelson G et al. (2005) Winter biological processes could help convert arctic tundra to shrubland. BioScience, 55, 17-26.

Sun J, Wang X, Chen A, Ma Y, Cui M, Piao S (2011) NDVI indicated characteristics of vegetation cover change in China's metropolises over the last three decades. Environmental Monitoring and Assessment, 179, 1-14.

Sweet SK, Gough L, Griffin KL, Boelman NT (2014) Tall deciduous shrubs offset delayed start of growing season through rapid leaf development $\mathrm{n}$ the Alaskan arctic tundra. Arctic, Antarctic, and Alpine Research, 46, 694-709.

Tagesson T, Mastepanov M, Tamstorf MP et al. (2012) High-resolution satellite data reveal an increase in peak growing season gross primary production in a high-arctic wet tundra ecosystem. 1992-2008. International Journal of Applied Earth Observation and Geoinformation, 18, 407-416.

Tape KD, Sturm M, Racine C (2006) The evidence for shrub expansion in northern Alaska and the Pan-Arctic. Global Change Biology, 12, 686-702.

Toms JD, Lesperance ML (2003) Piecewise regression: a tool for identifying ecological thresholds. Ecology, 84, 2034-2041.

Tucker CJ, Slayback DA, Pinzon JE, Los SO, Myneni RB, Taylor MG (2001) Higher northern latitude NDVI and growing season trends from 1982 to 1999. International Journal of Biometeorology, 45, 184-190.

Ueyama M, Iwata H, Harazono Y, Euskirchen ES, Oechel WC, Zona D (2013) Growing season and spatial variations of carbon fluxes of Arctic and boreal ecosystems in Alaska (USA). Ecological Applications, 23, 1798-1816.
Verbyla D (2008) The greening and browning of Alaska based on 1982-2003 satellite data. Global Ecology and Biogeography, 17, 547-555.

Vierling LA, Deering DW, Eck TF (1997) Differences in arctic tundra vegetation type and phenology as seen using bidirectional radiometry in the early growing season. Remote Sensing of Environment, 60, 71-82.

Vieth E (1989) Fitting piecewise linear regression functions to biological responses. Journal of Applied Physiology, 67, 390-396.

Wahren CHA, Walker MD, Bret-Harte MS (2005) Vegetation responses in Alaskan arctic tundra after 8 years of a summer warming and winter snow manipulation experiment. Global Change Biology, 6, 19-34.

Walker MD, Walker DA, Welker JM et al. (1999) Long-term experimental manipulation of winter snow regime and summer temperature in arctic and alpine tundra. Hydrological Processes, 13, 2315-2330.

Walker MD, Wahren CH, Hollister RD et al. (2006) Plant community response to experimental warming across the tundra biome. Proceedings of the National Academy of Science, USA, 103, 1342-1346.

Walther GR, Post E, Convey P et al. (2002) Ecological responses to recent climate change. Nature, 416, 389-395.

Wang X, Key JR (2003) Recent trends in Arctic surface, cloud, and radiation properties from space. Science, 299, 1725-1728.

Wang X, Piao S, Ciais P, Li J, Friedlingstein P, Koven C, Chen A (2011) Spring temperature change and its implication in the change of végetation growth in North America from 1982 to 2006. Proceedings of the National Academy of Sciences, 108, 1240-1245.

White MA, Thornton PE, Running SW (1997) A continental phenology model for monitoring vegetation responses to interannual climatic variability. Global Biogeochemical Cycles, 11, 217-234.

White MA, Brunsell N, Schwartz MD (2003) Vegetation phenology in global change studies. In: Phenology: An Integrative Environmental Science (ed. Schwartz MD), pp 453-466. Kluwer Academic Publishers, New York, NY, USA.

White MA, de Beurs KM, Didan K et al. (2009) Intercomparison, interpretation, and assessment of spring phenology in North America estimated from remote sensing for 1982-2006. Global Change Biology, 15, 2335-2359.

van Wijk MT, Williams M (2005) Optical instruments for measuring leaf area index in low vegetation: application in Arctic ecosystems. Ecological Applications, 15, 1462 1470 .

van Wijk MT, Williams M, Laundre JA, Shaver GR (2003) Interannual variability of plant phenology $n$ tussock tundra: modeling interactions of plant productivity, plant phenology, snowmelt and soil thaw. Global Change Biology, 9, 743-758.

van Wijk MT, Williams M, Shaver GR (2005) Tight coupling between leaf area index and foliage $\mathrm{N}$ content in arctic plant communities. Oecologia, 142, 421-427.

Wipf S (2010) Phenology, growth, and fecundity of eight subarctic tundra species in response to snowmelt manipulations. Plant Ecology, 207, 53-66.

Wookey PA, Aerts R, Bardgett RD et al. (2009) Ecosystem feedbacks and cascade processes: understanding their role in the response of arctic and alpine ecosystems to environmental change. Global Change Biology, 15, 1153-1172.

Xu L, Myneni RB, Chapin FS III et al. (2013) Temperature and vegetation seasonality diminishment over northern lands. Nature Climate Change, 3, 581-586.

Zeng H, Jia G, Epstein H (2011) Recent changes in phenology over the northern high latitudes detected from multi-satellite data. Environmental Research Letters, 6 045508.

Zhang X, Friedl MA, Schaaf CB et al. (2003) Monitoring vegetation phenology using MODIS. Remote Sensing Environment, 84, 471-475.

Zhang G, Zhang Y, Dong J, Xiao X (2013) Green-up dates in the Tibetan Plateau have continuously advanced from 1982 to 2011. Proceedings of the National Academy of Sciences, 110, 4309-4314.

Zhou LM, Tucker CJ, Kaufmann RK, Slayback D, Shabanov NV, Myneni RB (2001) Variations in northern vegetation activity inferred from satellite data of vegetation index during 1981-1999. Journal of Geophysical Research, 106, 2006920083 


\section{Supporting Information}

Additional Supporting Information may be found in the online version of this article:

Figure S1. Two-day averages of seasonal 2013 (a) air temperature (Celsius) and (b) photosynthetically active radiation (PAR) at two field sites used in this study in the northern foothills of the Brooks Range, Alaska. Error bars represent 1 standard error of the mean (SEM).

Figure S2. Percent cover of functional groups for deciduous shrub (DS) canopies (black bars) and evergreen/graminoid (EG) canopies (white bars). Bars represent averages for both sites ( $n=9$ per group, per cover type). ANOvA was used to compare means between DS and EG plots. Bars marked with different letters are significantly different from one another $(P<0.05)$ based on Tukey's HSD comparisons. Error bars represent 1 standard error of the mean (SEM).

Figure S3. Example of equipment assemblages in evergreen/graminoid (EG) canopy (left) and deciduous shrub (DS) canopy (right) used in this study to determine the normalized difference vegetation index (NDVI). Sensors collected photosynthetically active radiation (PAR), solar irradiance, and air temperature (Celsius) data every 2 min from 1 June to 5 September 2013.

Figure S4. Relationship between $\mathrm{NDVI}_{\text {broadband }}$ values derived from photosynthetically active radiation (PAR) and solar irradiance

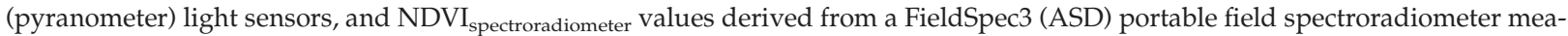
surements. Data represents daily averages from all 18 quadrats at each site (IMVT and SDOT) from 1 June to 16 July 2013 ( $n=140$ ).

Figure S5. Quadrat-level phenology modeling of seasonal loess smoothed NDVI curves of deciduous shrub canopies (DS - solid circles) and evergreen/graminoid canopies (EG - open circles). Horizontal lines extending to dates on the $x$-axis depict dates of onset of greening (first set of grey lines), (2) onset of peak green (black lines), and (3) onset of senescence (second set of grey lines). Dashed lines represent dates determined using threshold analysis, and solid lines represent dates determined using piecewise regression analysis. For phenology dates where both methods yielded the same results only a solid line is visible.

Table S1. Model parameters used to predict leaf area indices (LAI) using NDVI (Eqn 7: LAI $=a^{*} \mathrm{e}^{b^{*} \mathrm{NDVI}}$ ) based on best-fit exponential regression parameters for the LAI-NDVI relationship from table 2 in Street et al. (2007). Vegetation types selected for use in this study were based on aerial percent cover of our research areas compared to information in table 1 in Street et al. (2007). 